Andréa Tenório Correia da Silva

\title{
Estudo sobre esgotamento profissional e transtornos mentais comuns em agentes comunitários de saúde no município de São Paulo
}

\author{
Dissertação apresentada à Faculdade de \\ Medicina da Universidade de São Paulo, \\ para obtenção do título de Mestre em \\ Ciências
}

Área de Concentração: Medicina Preventiva

Orientador: Prof. Dr. Paulo Rossi Menezes

São Paulo 2008 
É expressamente proibida a comercialização deste documento tanto na sua forma impressa como eletrônica. Sua reprodução total ou parcial é permitida exclusivamente para fins acadêmicos e científicos, desde que na reprodução figure a identificação do autor, título, instituição e ano da dissertação. 
Aos meus queridos pais, Erivaldo e Vera, pelo amor e pela dedicação;

Aos meus queridos irmãos, Karla e Rodrigo, pelo carinho e incentivo permanentes. 


\section{AGRADECIMENTOS}

Ao Prof. Dr. Paulo Rossi Menezes, orientador competente, dedicado, sempre presente e que tem a habilidade de ensinar mantendo a motivação dos alunos pela beleza das descobertas.

À Profa. Dra. Lília Blima Schraiber, à Profa. Dra. Ana Flávia Pires Lucas D. Oliveira e ao Prof. Dr. Heráclito Barbosa de Carvalho pelas valiosas sugestões no exame de qualificação.

À Profa. Dra. Carla Gianna Luppi, pela importante participação na minha formação acadêmica e pelo incentivo para estudar as questões ligadas ao PSF, sempre motivando a busca de respostas.

Às minhas duas equipes de saúde da família (CSE Alexandre Vranjac e UBS Vila Dalva) pelos ensinamentos, por dias intensos, de trabalho incessante, de idéias e tantas construções, guiadas pela necessidade de transformar, de fazer acontecer, de sonhar.

Aos amigos queridos de longas e importantes jornadas: Anete, Benvinda, Débora, Gisele, Márcia Ernani, Márcia Nardi e Waldemir. 
Aos grandes companheiros de PSF da UBS Vila Dalva: Mariana, Gustavo, Simone, Ricardo e, em especial, à Patrícia Tello pela grande amizade e apoio em todas as horas.

À Patrícia Pereira De Salve, gerente da UBS Vila Dalva, pela confiança no meu trabalho no PSF e por acreditar na importância dessa pesquisa.

A todos os agentes comunitários de saúde que participaram dessa pesquisa. 
Eu agora vou falar do agente comunitário

Sempre pronto prá ajudar

Vive quase sem salário

Seu filho não quer comer?

Sempre dá muito trabalho?

Fale com o seu agente comunitário

Sua tia morreu

E não tem traje mortuário?

Fale com o seu agente comunitário

Seu marido te bateu?

Porque é um salafrário

Fale com o seu agente comunitário

O marido da vizinha não recebeu o salário?

Fale com o seu agente comunitário

Seu sapato tá apertado?

Tá machucando seu calo?

Fale com o seu agente comunitário

O seu nome está sujo?

Não pagou o crediário?

Fale com o seu agente comunitário

O seu patrão não oferece

Boas condições de trabalho?

Fale com o seu agente comunitário

Você foi à Unidade

E sumiu seu prontuário?

Fale com o seu agente comunitário

Tô pirando, tô pirado

Tô pirando, tô pirado!

Paciente, usuário

Peço pelo amor de Deus

Salve seu agente comunitário!

(Lenise Morreira Ferreira - Agente Comunitária de Saúde) 


\section{SUMÁRIO}

Lista de siglas

Lista de gráficos

Lista de tabelas

Resumo

Summary

1 INTRODUÇÃO 20

2 CONTEXTUALIZAÇÃO DAS QUESTÕES DE INVESTIGAÇÃO 23

2.1 O Programa de saúde da família e o agente $\begin{array}{ll}\text { comunitário de saúde } & 23\end{array}$

2.2 Esgotamento profissional (síndrome de burnout) 32

2.2.1 Definições

2.2.2 Modelos conceituais $\quad 36$

$\begin{array}{ll}\text { 2.2.3 Dados quantitativos } & 39\end{array}$

2.2.3.1 Fatores precipitantes $\quad 40$

2.2.3.2 Fatores de proteção 43

2.2.3.3 Conseqüências para o trabalhador e para as organizações $\quad 45$

2.3 Transtorno mental comum $\quad 46$

$\begin{array}{ll}3 \text { JUSTIFICATIVA } & 49\end{array}$

4 OBJETIVOS $\quad 50$

5 MÉTODO 51

5.1 DESENHO E AMOSTRA

5.2 INSTRUMENTOS 
5.2.1 Questionário com os dados: sociodemográficos, relacionados ao trabalho e à saúde dos sujeitos

5.2.2 Self Reporting Questionnaire 54

5.2.3 Maslach Burnout Inventory

5.2.4 Dados do Sistema de Informação da Atenção Básica 58

$\begin{array}{ll}5.3 \text { PROCEDIMENTOS } & 59\end{array}$

$\begin{array}{ll}\text { 5.3.1 Pré-Teste } & 59\end{array}$

$\begin{array}{ll}\text { 5.3.2 Pesquisa de Campo } & 60\end{array}$

5.4 ANÁLISE DOS DADOS 61

5.4.1 Variáveis de desfecho $\quad 61$

5.4.2 Variáveis de exposição $\quad 61$

6 CONSIDERAÇÕES ÉTICAS 66

$\begin{array}{ll}7 \text { RESULTADOS } & 67\end{array}$

$\begin{array}{ll}\text { 7.1 CARACTERÍSTICAS DA AMOSTRA } & 67\end{array}$

7.2 NÍVEIS DE ESGOTAMENTO PROFISSIONAL

7.3 CARACTERÍSTICAS INDIVIDUAIS E DO TRABALHO

ASSOCIADAS AO ESGOTAMENTO

7.3.1 Exaustão Emocional

$\begin{array}{ll}\text { 7.3.2 Despersonalização } & 77\end{array}$

7.3.3 Decepção

7.4 PREVALÊNCIA DE TRANSTORNO MENTAL COMUM E CARACTERISTICAS ASSOCIADAS 
7.5 TRANSTORNO MENTAL COMUM E ESGOTAMENTO $\begin{array}{lr}\text { PROFISSIONAL } & 89\end{array}$

8 DISCUSSÃO 91

8.1 SUMÁRIO DOS RESULTADOS 91

8.2 LIMITAÇÕES METODOLÓGICAS 91

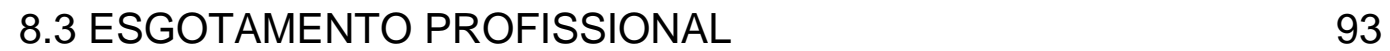

8.3.1 Exaustão emocional 96

8.3.2 Despersonalização 99

$\begin{array}{ll}\text { 8.3.3 Decepção } & 100\end{array}$

8.3.4 Aspecto adicional relacionado ao esgotamento 101

$\begin{array}{ll}\text { 8.4 TRANSTORNO MENTAL COMUM } & 102\end{array}$

8.5 ESGOTAMENTO PROFISSIONAL E TRANSTORNO

$\begin{array}{ll}\text { MENTAL COMUM } & 104\end{array}$

8.6 IMPLICAÇÕES PARA ORGANIZAÇÕES DE SERVIÇOS

$\begin{array}{ll}\text { E PARA PESQUISA } & 106\end{array}$

9 REFERÊNCIAS BIBLIOGRÁFICAS 108

$\begin{array}{ll}\text { ANEXOS } & 117\end{array}$

ANEXO 1 - Questionário com os dados: sociodemográficos, relacionados ao trabalho e à saúde dos entrevistados 117

$\begin{array}{ll}\text { ANEXO2 - Self reporting questionnaire } & 119\end{array}$

$\begin{array}{lr}\text { ANEXO3 - Maslach burnout inventory } & 120\end{array}$

$\begin{array}{ll}\text { ANEXO4 -Termo de consentimento livre e esclarecido } & 122\end{array}$ 


\section{LISTA DE SIGLAS}

ACS - Agentes Comunitários de Saúde

BIRD - Banco Internacional para a Reconstrução e o

Desenvolvimento

CID 10 - Classificação Internacional de Doenças

CIDI - Composite International Diagnostic Interview

ESF - Equipe de Saúde da Família

GHQ -12 - General Health Questionnaire

$\mathrm{MBI}$ - Maslach Burnout Inventory

MS - Ministério da Saúde

PACS - Programa de Agentes Comunitário de Saúde

PROESF - Projeto de Implantação e Consolidação do Programa

Saúde da Família

PSF - Programa Saúde da Família

SIAB - Sistema de Informação de Atenção Básica

SRQ-20 - Self Reportinging Questionnaire

SUS - Sistema Único de Saúde

TMC - Transtorno Mental Comum

UBS - Unidade Básica de Saúde

WHO - World Health Organization 


\section{LISTA DE FIGURAS}

Figura 1 Meta e Evolução do Número de Agentes Comunitários de Saúde no BRASIL - 1994 a 2007

Figura 2 Evolução da População Coberta por Agentes Comunitários de saúde no BRASIL - 1994 a 2007

Figura 3 Modelo de Freudenberger 36

Figura 4 Modelo de Leiter

Figura 5 Modelo estrutural de burnout

Figura 6 Mapa do município de São Paulo de acordo com as subprefeituras e distritos 


\section{LISTA DE TABELAS}

Tabela 1- Distribuição dos participantes de acordo com as Unidades Básicas de Saúde, São Paulo (N=141)

Tabela 2 - Distribuição dos entrevistados segundo as características sociodemográficas e socioeconômicas, São Paulo (N=141). 68

Tabela 3 - Distribuição dos sujeitos quanto às características relacionadas ao trabalho, São Paulo (N=141).

Tabela 4 - Descrição das características das microáreas de acordo com dados do SIAB, São Paulo ( $N=141)$.

Tabela 5 - Distribuição dos sujeitos de acordo com as dimensões do esgotamento, São Paulo ( $\mathrm{N}=141)$.

Tabela 6 - Distribuição dos sujeitos de acordo com as subescalas exaustão emocional e despersonalização e níveis de comprometimento, São Paulo (N=141).

Tabela 7 - Distribuição dos sujeitos de acordo com as dimensões exaustão emocional e despersonalização e níveis de comprometimento, São Paulo ( $\mathrm{N}=141)$.

Tabela 8 - Distribuição dos entrevistados de acordo com as subescalas despersonalização e decepção e os níveis de comprometimento, São Paulo (N=141). 
Tabela 9 - Odds ratio para exaustão emocional, segundo variáveis sociodemográficas, São Paulo (N=141).

Tabela 10 - Odds ratio para exaustão emocional, segundo a unidade básica de saúde, São Paulo (N=141).

Tabela 11 - Odds ratio para exaustão emocional, segundo variáveis relacionadas ao trabalho dos sujeitos e à microárea, São Paulo ( $\mathrm{N}=141)$.

Tabela 12 - Odds ratio para despersonalização, de acordo com as características sociodemográficas, São Paulo ( $N=141)$.

Tabela 13 - Odds ratio para despersonalização, de acordo com as unidades básicas de saúde, São Paulo (N=141).

Tabela 14 - Odds ratio para despersonalização, segundo as características do trabalho e da microárea, São Paulo (N=141).

Tabela 15 - Odds ratio para decepção, de acordo com as características sociodemográficas, São Paulo ( $\mathrm{N}=141)$.

Tabela 16 - Odds ratio para decepção, segundo unidade básica de Saúde dos entrevistados, São Paulo (N=141).

Tabela 17 - Odds ratio para decepção, de acordo com as características do trabalho e da microárea, São Paulo (N=141). 
Tabela 18 - Odds ratios brutos e ajustados para as dimensões do esgotamento, segundo as variáveis que permaneceram nos modelos da regressão logística multivariável, São Paulo, (N=141).

Tabela 19 - Odds ratio para transtorno mental comum, de acordo com as variáveis sociodemográficas, São Paulo (N=141).

Tabela 20 - Odds ratio para TMC, de acordo com as unidades básicas de saúde, São Paulo (N=141).

Tabela 21 - Odds ratio para TMC, segundo as características do trabalho e da microárea, São Paulo (N=141).

Tabela 22 - Odds ratio para transtorno mental comum, de acordo com as dimensões do esgotamento, São Paulo, (N=141).

Tabela 23 - Odds ratios brutos e ajustados para transtorno mental comum, de acordo com as variáveis que permaneceram no modelo final de regressão multivariável, São Paulo, (N=141). 


\section{RESUMO}

Silva, ATC. Estudo sobre esgotamento profissional e transtornos mentais comuns em agentes comunitários de saúde no município de São Paulo [dissertação de mestrado]. São Paulo: Faculdade de Medicina da USP; 2008.

Introdução - O Programa de Saúde da Família (PSF) é atualmente responsável pelo cuidado da saúde de 86,7 milhões de pessoas, empregando um grande contingente de profissionais, dentre eles os agentes comunitários de saúde (ACS). O trabalho dos ACS envolve particularidades que podem estar associadas a grandes pressões e dificuldades na realização de suas atribuições. Objetivo - Investigar a ocorrência da síndrome do esgotamento profissional e de transtornos mentais comuns em agentes comunitários de saúde do PSF do município de São Paulo e estudar possíveis fatores associados. Método - estudo transversal com 141 agentes comunitários em 6 unidades básicas de saúde da região centro-oeste. Três questionários foram aplicados: características sociodemográficas e do trabalho, o Self Reporting Questionnaire e o Maslach Burnout Inventory. Foi utilizada a regressão logística multivariada para verificar associações independentes. Resultados - Níveis moderados ou altos de exaustão emocional foram observados em 70,9\% dos participantes, de despersonalização em 34\% e decepção em 47,5\%. A prevalência de TMC foi 43,3\% (IC95\% 35,0 a 51,5). A análise multivariada evidenciou os fatores de risco para os desfechos: a) exaustão emocional: 
níveis de decepção moderado ou alto b) despersonalização: ter exaustão moderada ou alta e possuir $20 \%$ da população cadastrada na microárea com destino do lixo queimado ou a céu aberto; c) decepção: exaustão emocional moderada ou alta; d) transtorno mental comum: exaustão moderada ou alta e decepção moderada ou alta. Conclusões - A elevada ocorrência de transtornos mentais comuns e de níveis intensos de esgotamento profissional nos agentes comunitários de saúde suscitam a necessidade de estratégias de intervenção individuais e organizacionais e de novas investigações sobre determinantes de esgotamento profissional e TMC nessa categoria de trabalhadores.

Descritores: Estafa profissional, transtornos mentais, pessoal da saúde, programa saúde da família, saúde do trabalhador 


\section{SUMMARY}

Silva, ATC. Burnout syndrome and common mental disorders among community health workers in Sao Paulo [dissertation]. Faculty of Medicine, University of Sao Paulo, SP (Brazil); 2007.

Aim: To investigate the occurrence of burnout syndrome and common mental disorders among community health workers from the Family Health Program in the city of Sao Paulo and to study associated factors.

Method: A cross-sectional survey with 141 community health workers who had been on that activity for at least 6 months in 6 primary care units was carried out. We used 3 questionnaires: socio-demographic and work-related characteristics, the Self Reportinging Questionnaire, and Maslach Burnout Inventory, which allows the assessment of 3 dimensions of burnout: emotional exhaustion, depersonalization and reduced personal accomplishment. Logistic regression analysis was used to examine independence of associations.

Results: Moderate or high levels of emotional exhaustion, depersonalization and reduced personal accomplishment were observed among $70.9 \%, 34.0 \%$ and $47.5 \%$ of the participants, respectively. The prevalence of common mental disorders was $43.3 \%$. We observed positive correlations among 3 dimensions of burnout. Presence of common mental disorder was independently associated with high levels of emotional exhaustion and reduced personal accomplishment. 
Conclusions: The high frequency of intense levels of burnout and the high prevalence of common mental disorders among community health agents point to the need of strategies for improving their working conditions and further studies to understand better the present picture and the determinants of burnout in this group of health workers.

Descriptors: burnout professional, health personnel, mental disorders, family health program, occupational health 


\section{INTRODUÇÃO}

Na última década, a síndrome do esgotamento profissional (burnout) e os transtornos mentais comuns (TMC) têm sido cada vez mais identificados e pesquisados entre os profissionais de saúde, principalmente médicos e enfermeiras (ALUJA, 1997; PROSSER e col., 1999; McMANUS e col., 2002).

De acordo com a literatura mundial, a relevância de estudar esses temas está nas repercussões que o esgotamento profissional e os TMC trazem para o profissional e sua família, para a população que recebe a assistência e para a organização na qual o profissional trabalha. Tais repercussões incluem: absenteísmo, incapacitação, queda da produtividade e do comprometimento organizacional, alta rotatividade de profissionais, elevação da demanda dos serviços de saúde, uso abusivo de tranqüilizantes, álcool e outras drogas, influenciando as relações familiares e sociais, e gerando grandes perdas de recursos humanos e econômicos (DELGADO,1993; MASLACH e LEITER,1997; TAMAYO e TRÓCCOLI, 2002).

No Brasil, em 1991 o Ministério da Saúde (MS) criou o Programa de Agentes Comunitários de Saúde (PACS), ampliado em 1994 para o Programa Saúde da Família (PSF), e incorporou nas equipes de saúde uma nova classe de trabalhadores, o agente comunitário de saúde (ACS). 
O ACS é considerado o elo entre as equipes de saúde e a comunidade, pois vivencia a realidade e as práticas de saúde do bairro onde mora e trabalha (MS,1998; NUNES e col., 2002).

O MS deu grande prioridade ao PSF e foram feitos grandes investimentos na implantação e ampliação do programa. Desse modo, o orçamento nacional para o PSF passou de R\$ 970 milhões em 2001 para $R \$ 1,3$ bilhões em 2002, e em 2004, iniciou-se o PROESF (Projeto de Implantação e Consolidação do Programa de Saúde da Família), um acordo de empréstimo entre o governo brasileiro e o Banco Internacional para a Reconstrução e o Desenvolvimento (BIRD), com investimentos para expansão, consolidação e qualificação da estratégia nos grandes centros urbanos (acima de 100 mil habitantes), incluindo a ampliação da capacitação dos profissionais na área de atenção à saúde e a institucionalização de sistemas de avaliação e de monitoramento do PSF (MS, 2004).

Como conseqüência da ampliação do PSF no país, uma imensa quantidade de profissionais foi contratada, já que cada equipe de saúde da família (ESF) é composta por um médico, uma enfermeira, um a dois auxiliares de enfermagem e 4 a 6 ACS. Esses profissionais começaram a desenvolver um trabalho novo, para o qual há uma diretriz, mas não há um modelo único, nem experiência acumulada que possibilitem lidar com as questões que surgem no cotidiano das ESF, em vários momentos 
ultrapassando os limites da assistência à saúde, e suscitando a necessidade de ações intersetoriais. Na maior parte das vezes, as ESF não contam com essa rede interdisciplinar funcionando e lidam com as dificuldades da população cadastrada de acordo com os recursos disponíveis e a criatividade dos componentes das equipes.

Diante desse cenário, é necessário estudar as condições de saúde dos trabalhadores do PSF, em especial os ACS, que constituem a categoria profissional mais recentemente incorporada à equipe de saúde e que está sujeita a uma dinâmica laboral particular de viver e trabalhar na mesma comunidade, o que pode gerar pressões e sobrecargas adicionais. O presente trabalho enfoca a identificação da síndrome do esgotamento profissional e dos transtornos mentais comuns em ACS da cidade de São Paulo, e os fatores sociodemográficos, socioeconômicos e do trabalho associados ao esgotamento profissional e aos transtornos mentais comuns. 


\section{CONTEXTUALIZAÇÃO DAS QUESTÕES DE INVESTIGAÇÃO}

\subsection{O Programa de Saúde da Família e o agente comunitário de saúde}

O PSF surgiu como um projeto estruturante do SUS, com a proposta de ampliação do lócus de intervenção em saúde, incorporando na sua prática o domicílio e os espaços comunitários diversos, contribuindo para o fortalecimento do vínculo entre os profissionais das equipes e a comunidade, gerando um conhecimento das reais necessidades da população e tornando possível que as intervenções sejam elaboradas de acordo com a situação específica local (SOUSA, 2001; NUNES e col., 2002).

Foi nesse sentido que o Ministério da Saúde $(1994,1998)$ estabeleceu como objetivo geral do PSF a reorientação do modelo assistencial a partir da atenção básica, em conformidade com os princípios do Sistema Único de Saúde (SUS). Os objetivos específicos são:

1. prestar assistência contínua, integral, com resolubilidade e de boa qualidade às necessidades de saúde da população adscrita;

2. intervir sobre os fatores de risco aos quais a população está exposta; 
3. eleger a família e o seu espaço social como núcleo básico de abordagem no atendimento à saúde;

4. humanizar as práticas de saúde através do estabelecimento de um vínculo entre os profissionais de saúde e a população;

5. proporcionar o estabelecimento de parcerias através do desenvolvimento de ações intersetorias;

6. contribuir para a democratização do conhecimento do processo saúdedoença, da organização dos serviços;

7. fazer com que a saúde seja reconhecida como um direito de cidadania e, portanto, expressão da qualidade de vida;

8. estimular a organização da comunidade para efetivo exercício do controle social.

Os investimentos do Ministério da Saúde, visando ampliar cada vez mais a população coberta pelos PACS/PSF, têm sido progressivamente mais altos. Em 2004, a primeira fase do PROESF contou com o volume total de recursos de US\$ 550 milhões, sendo 50\% advindo do BIRD e 50\% do governo federal, e há a previsão de estar totalmente implantado até 2008 (MS, 2004).

A norma operacional básica $01 / 96$ do MS contribuiu para a consolidação do programa, pois modificou a lógica de financiamento, que anteriormente era baseada na produção de serviços, passando a estabelecer o pagamento em função da cobertura populacional. A portaria $n^{\circ} 1.329$ 
prescreve que, de acordo com a faixa de cobertura, os municípios passam a receber incentivos diferenciados. Desse modo, por exemplo, um município com faixa de cobertura de até 4,9\% recebe por equipe por ano, $R \$ 28.000$, enquanto outro com cobertura entre 50 e $59,9 \%$ recebe $R \$$ 47.160 por equipe por ano (MS, 2000).

Assim, a implantação do PSF no país tem sido exponencial: em 1994 havia 300 ESF implantadas cobrindo 1,1 milhão de pessoas; em 2007 o Ministério da Saúde registrou mais de 27.000 ESF e cobertura de 86,7 milhões de habitantes. O número de ACS aumentou de 29 mil em 1994 para 135 mil em 2000 e chegou a 219 mil em fevereiro de 2007 (figura 1). É assim que, atualmente, os ACS são responsáveis pelo acompanhamento de aproximadamente 109 milhões de pessoas (figura 2) (MS, 2007). 
Figura 1 - Evolução do número de Agentes Comunitários de Saúde no BRASIL - 1994 a 2007

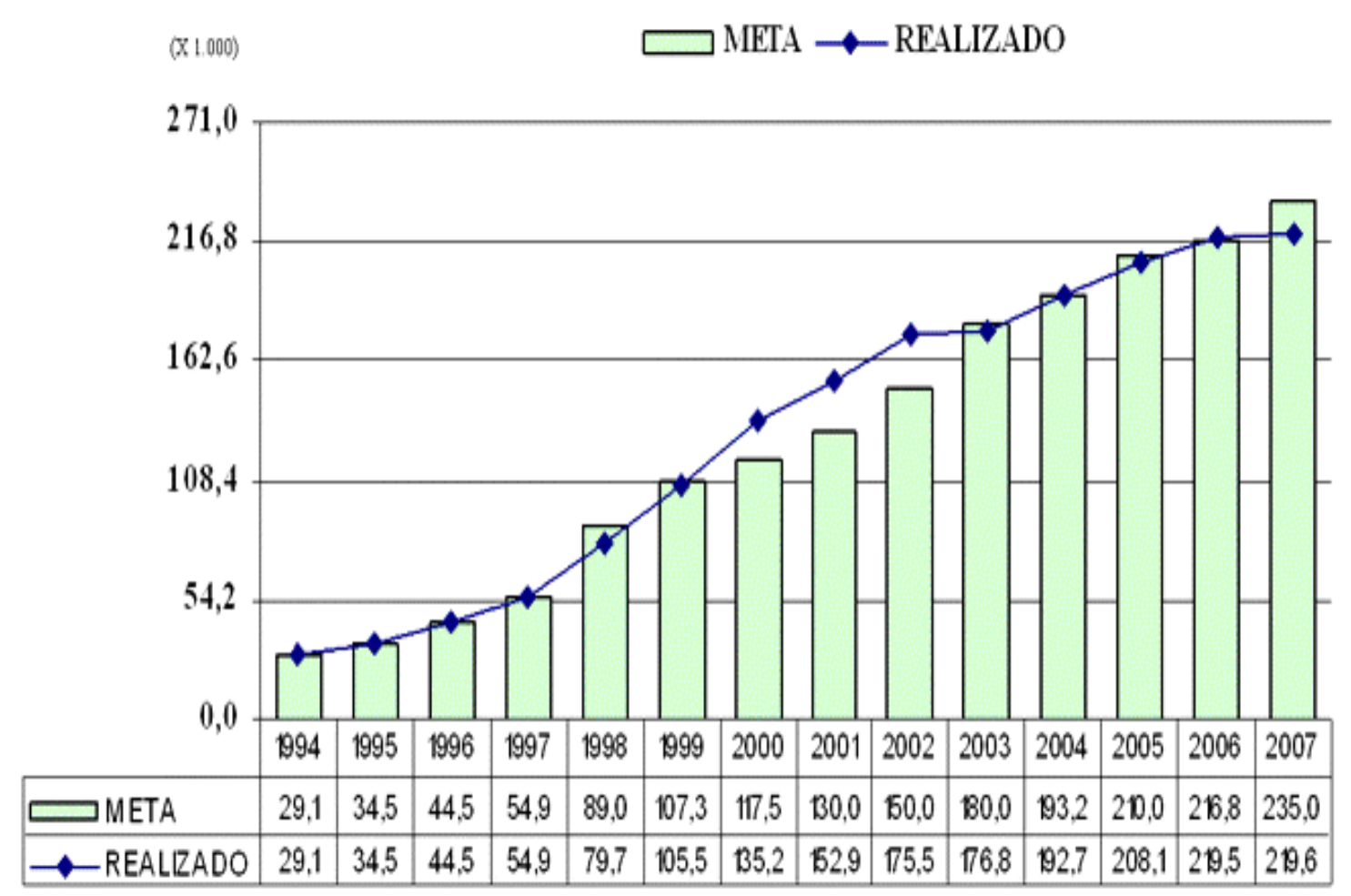

FONTE: SUAB - Sustema de intormachio da Atenç̧ó Básica 
Figura 2 - Evolução da população coberta por Agentes Comunitários de Saúde no BRASIL - 1994 a 2007

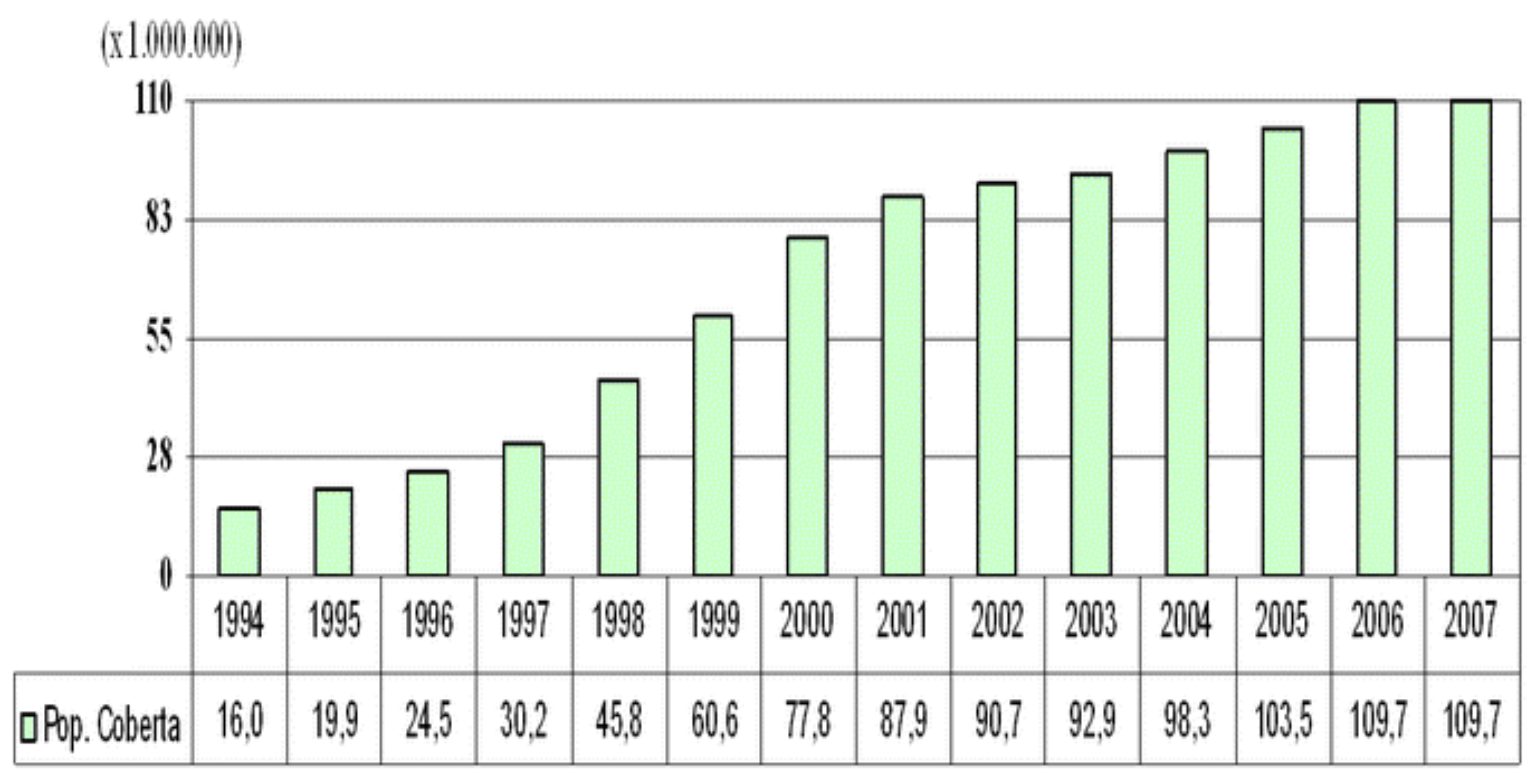

FOMTE: SIAB - Sistema de Irfenmaçăo da Atençăo Bissica

De acordo com dados da Secretaria Municipal de Saúde de São Paulo (SMS, 2004), das 368 unidades básicas de saúde do município, 211 funcionam com ESF. São 645 equipes de PSF e 128 equipes de PACS, atendendo 2,6 milhões de pessoas, que correspondem a $22 \%$ da população do município.

De acordo com a Política Nacional de Atenção Básica (MS, 2004), a ESF trabalha em regime de dedicação integral e deve ser formada por, no mínimo, um médico, um enfermeiro, um auxiliar ou técnico de enfermagem e 4 a 6 ACS. As Equipes tornam-se responsáveis pela população adscrita, que é composta em média por 3000 pessoas, com o limite de 4000 
indivíduos (cada ACS assume uma microárea, com limite de 750 pessoas), e têm a co-responsabilidade social de enfrentar os desafios de uma nova produção de saúde, tendo como base a atenção às famílias, considerandoas em todos os seus espaços de vida (SOUSA, 2001).

Diante do exposto, verifica-se que o ACS se tornou, na última década, um novo ator político no cenário da assistência à saúde, tendo contato permanente com as famílias cadastradas na microárea, realizando visitas domiciliares mensais e tendo participação fundamental na vigilância e promoção da saúde. É também um elo cultural, que faz a ponte entre o saber científico e do saber popular (MS, 1998). Desse modo, é percebido como alguém identificado com a própria comunidade, com os mesmos valores, costumes, linguagem, cuja capacidade de liderança se reverte em ação em prol da melhoria das condições de vida da população (SOUZA, 2001). Para SILVA e DALMASO (2004), o ACS é considerado sujeito de viabilização de políticas de saúde de uma nova linguagem, e seu trabalho, de modo geral, ultrapassa o atendimento às necessidades, pois se dedica a cuidar da comunidade e pensar a saúde em sua concepção ampliada. Esses atributos do ACS se articulam à inserção desse trabalhador em Programas fundamentados na humanização da assistência e no vínculo de co-responsabilidade estabelecido entre os serviços de saúde e a população, oferecendo a possibilidade de reestruturação da atenção primária a partir de ações conjugadas, seguindo os princípios de territorialização, intersetorialidade, descentralização e priorização de 
grupos populacionais com maior risco de adoecer (NUNES e col., 2002; LEVY e col., 2004; MS, 1998).

Em 1994, o MS estabeleceu as atribuições dos ACS:

1. Realizar mapeamento de sua área de atuação;

2. Cadastrar e atualizar as famílias da microárea, identificando indivíduos expostos a situações de risco;

3. Acompanhar todas as famílias sob sua responsabilidade através das visitas domiciliares mensais;

4. Coletar dados para análise da situação das pessoas acompanhadas;

5. Desenvolver ações básicas de saúde nas áreas de atenção à criança, à mulher, ao adolescente, ao trabalhador e ao idoso, com ênfase na promoção da saúde e prevenção de doenças;

6. Promover educação em saúde e mobilização comunitária, visando a uma melhor qualidade de vida através de ações de saneamento e melhorias do meio ambiente;

7. Incentivar a formação dos conselhos locais de saúde;

8. Orientar as famílias para a utilização adequada dos serviços de saúde acerca da dinâmica social da comunidade, suas disponibilidades e necessidades, participação no processo de programação e planejamento local das ações relativas ao território de abrangência da Unidade de Saúde, com objetivo de superar os problemas identificados.

De acordo com o Ministério da Saúde (1998), o ACS deve residir na área em que atua, pois assim tem a vivência do cotidiano da comunidade. Cabe 
ao ACS discernir quais informações devem ser compartilhadas com o restante da equipe, quais são relevantes para gerar benefícios para a comunidade e orientar as ações. Ao operacionalizar esse trabalho, é importante considerar a privacidade do próprio ACS (FORTES e SPINETTI, 2004).

A profissão de ACS foi regulamentada apenas em 2002, lei 10.501, cerca de onze anos após a criação do PACS (MS, 2002) e a identidade profissional do ACS, ao contrário dos outros membros da equipe, que possuem um papel bem definido, ainda está em construção.

SILVA e DALMASO (2004) avaliaram a construção da identidade profissional do ACS com base em quatro dimensões, que se articulam: a profissão e sua regulamentação; a organização do trabalho burocrática e profissionalmente; o pertencimento a um grupo profissional e a grupo social; e as diferentes modalidades de assistência em saúde. Essas autoras descrevem que como o ACS não possuía uma formação específica fornecida por alguma instituição, não era, a princípio, um profissional no sentido estrito. Havia a percepção do ACS como indivíduo que conhecia a população, organizava o acesso à unidade de saúde, observava situações de risco e a adesão aos cuidados de saúde proposto pelo médico e enfermeiro, mas havia pouca identificação com as ações de educação em saúde. A valorização das atividades assistenciais era reforçada na capacitação proposta para os ACS, apesar dos conflitos vivenciados 
constantemente por presenciarem muitas situações de desigualdade social e ausência de direitos, sem um saber sistematizado e instrumentos apropriados para lidar com essas questões.

PEDROSA e TELES (2001), ao estudar consensos e diferenças nas ESF, assinalam a contradição que os ACS descrevem entre sua situação de morador da comunidade e a condição de integrante da equipe de saúde, reivindicando benefícios de programas de proteção social, como melhoria habitacional, planos de saúde e insalubridade. Outro ponto que gera contradição é o fato do ACS vivenciar a realidade e as práticas de saúde do bairro onde mora e trabalha, e ser formado a partir de referenciais biomédicos, o que também contribui para a possibilidade de diálogo entre esses saberes e práticas (NUNES e col., 2002).

$\mathrm{Na}$ opinião dos médicos das ESF de Teresina, sobre a organização do processo de trabalho e as relações na equipe, um dos problemas que aparece é a indefinição do papel do ACS na relação médico/paciente/serviço, dúvidas se o ACS deve atuar ou opinar nas intervenções diagnósticas ou terapêuticas, participar no levantamento de dados e facilitar o acesso ao serviço pela população (PEDROSA e TELES, 2001).

Alguns autores também questionam qual seria a condição de autonomia do ACS em face ao processo de trabalho, que técnicas ele disporia para 
intervenções próprias ao seu desempenho, ou se ficaria restrito a executar tarefas segundo um conjunto de normas e regras profissionais administrativamente definidas, que muitas vezes não condizem com a realidade enfrentada (DALMASO e SILVA, 2004).

Para NUNES e col. (2002) acrescentam que as expectativas em torno do trabalho do ACS são heterogêneas: "Enquanto a comunidade o inscreve em uma demanda predominantemente pessoal, a equipe de saúde espera uma prática mais técnica e pedagógica. Os ACS, por sua vez, somam a expectativa de uma competência técnica a valores e conhecimentos que estão arraigados à sua cultura, e que entram em choque com aquela primeira" (p. 1646).

\subsection{ESGOTAMENTO PROFISSIONAL (SÍNDROME DE BURNOUT)}

O termo burnout (queimar completamente) foi utilizado pela primeira vez por FREUDENBERGER (1974), para descrever um quadro de sintomas psicológicos e comportamentais relacionados à atividade laboral, quando observou que jovens que trabalhavam como voluntários numa instituição de reabilitação de dependentes de drogas começaram a apresentar uma diminuição gradual de energia, da motivação e do comprometimento, acompanhados de sintomas físicos e psíquicos, sentimento de fracasso e exaustão. Em geral, esses sintomas predominavam em indivíduos que 
trabalhavam na prestação de cuidados a pessoas doentes, grupos sociais carentes ou crianças, e profissionais afetados desenvolviam uma verdadeira intolerância ao contato com aqueles que antes eram alvo de dedicação. Em 1975, o mesmo autor descreveu uma síndrome caracterizada pela presença de manifestações depressivas, aumento da irritação, perda de disposição, decepção, agressividade, perturbações do sono e perda do interesse pelo trabalho (FREUDENBERGER, 1975).

Outra pesquisadora pioneira em estudos sobre esgotamento profissional é a psicóloga social Christina Maslach, que observou como as pessoas que trabalhavam nos serviços humanitários lidavam com a carga emocional do trabalho. Em 1981, juntamente com Suzan Jackson, publicaram o Maslach Burnout Inventory (MBI) (MASLASH e JACKSON, 1981). A partir da década de 90 , as pesquisas sobre esgotamento profissional se tornaram cada vez mais freqüentes na literatura mundial, principalmente estudos com profissionais das áreas da saúde e educação, cujo trabalho se articula com a necessidade de manter contato direto e constante com outras pessoas (DELGADO, 1993; CHERNISS, 1992; SCHAUFELI e ENZMANN, 1998; ALOHA, 2006). 


\subsubsection{Definições}

A partir da proposição de FREUDENBERGER (1975), outros pesquisadores elaboraram definições para a síndrome do esgotamento: resposta prolongada a estressores emocionais e interpessoais crônicos no trabalho, geralmente levando a uma deterioração do bem-estar físico e emocional; uma forma de estresse laboral, correspondendo a etapa final das progressivas tentativas mal-sucedidas do indivíduo em lidar com o estresse decorrente de condições de trabalho; estado de exaustão psicológica causada pelo envolvimento prolongado com situações que são absorventes emocionalmente (MASLACH e JACKSON, 1981; LEITER, 1993).

Vários autores consideram a síndrome um fenômeno constituído por 3 dimensões (MASLACH e JACKSON, 1981; CHERNISS,1992; MASLACH e LEITER, 1997):

1. Exaustão Emocional: que é o fator central do esgotamento, caracteriza-se pelo sentimento de desgaste emocional e falta de energia, e possui uma correlação inversa com desempenho no trabalho (WRIGHT e CROPANZANO, 1998). Geralmente está relacionada às excessivas demandas do trabalho, aos conflitos pessoais e aos sintomas: cefaléia, mialgia, alterações gastro-intestinais, hipertensão e alterações do sono. 
2. Despersonalização (desumanização): o afastamento psicológico surge como estratégia defensiva e o profissional apresenta ansiedade, aumento da irritabilidade, perda de motivação, redução do idealismo e conduta voltada para si mesmo, passando a tratar os clientes, colegas e a organização como objetos, podendo demonstrar uma insensibilidade emocional.

3. Reduzida realização pessoal (decepção): tendência do trabalhador a autoavaliar-se de forma negativa, sentir-se infeliz e insatisfeito com seu desenvolvimento profissional, surge um sentimento de incompetência e inadequação.

Analisando as definições de esgotamento profissional, SCHAUFELI e BUUNK (1996) descrevem cinco características comuns:

a) relevância dos sintomas mentais e comportamentais. Os sintomas físicos são mencionados por vários autores;

b) predomínio de sintomas disfóricos, especialmente exaustão emocional;

c) é observado em indivíduos normais;

d) geralmente está relacionado ao trabalho;

e) A diminuição da efetividade e do desempenho no trabalho aparecem como conseqüência das atitudes e comportamentos negativos. 


\subsubsection{Modelos conceituais}

Na descrição de FREUDENBERGER (1974) haveria uma primeira fase de entusiasmo, alta expectativas e idealização, passando para uma fase de paralisia e depois de frustração, na qual seria questionada a utilidade do trabalho, destacando-se todas as dificuldades e aspectos negativos, e aparecendo os problemas emocionais e de conduta. Por fim, se desenvolveria um estado de apatia ou indiferença em relação ao trabalho.

Figura 3. Modelo de Freudenberger (1974)

Entusiasmo

Altas Expectativas $\longrightarrow$ Paralisia $\longrightarrow$ Frustação $\longrightarrow$ Apatia Idealização

Outra possibilidade é que inicialmente surgiria a exaustão emocional, desencadeada pela sobrecarga de trabalho e demandas interpessoais. Para lidar com a exaustão o trabalhador desenvolveria atitudes de defesa (isolamento e indiferença de tratamento) aparecendo a despersonalização e, seria a falta de recursos pessoais e institucionais que levaria tanto à despersonalização quanto à baixa realização pessoal (LEITER, 1993) (figura 4). 
Figura 4- Modelo de Leiter (1993)

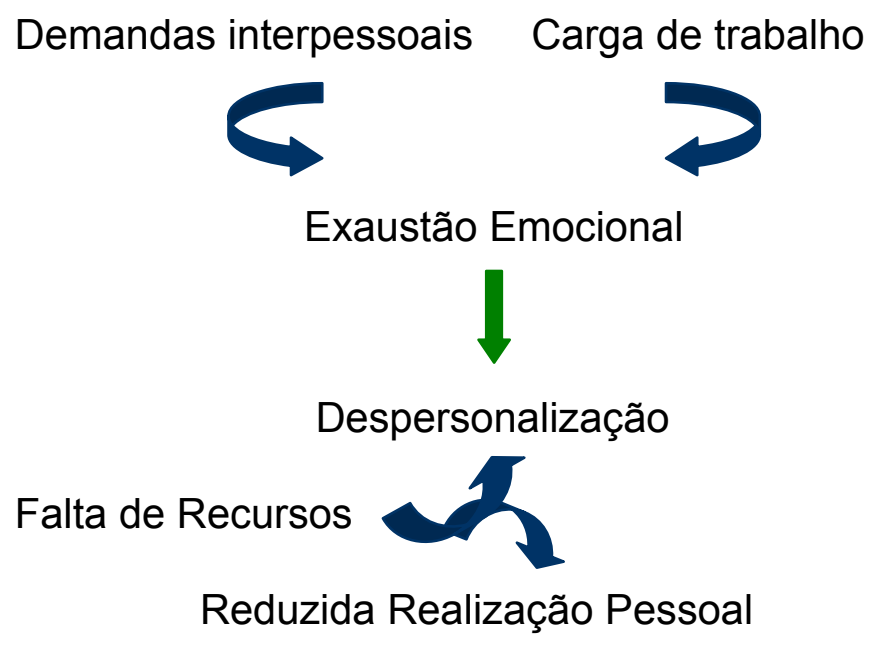

Fonte: Leiter, 1993

Já o modelo estrutural do esgotamento elaborado por MASLACH e col. (1996) identifica preditores para cada uma das dimensões da síndrome, em geral, incluem as demandas de trabalho e falta de recursos (figura 5). 
Figura 5 - Modelo estrutural do burnout
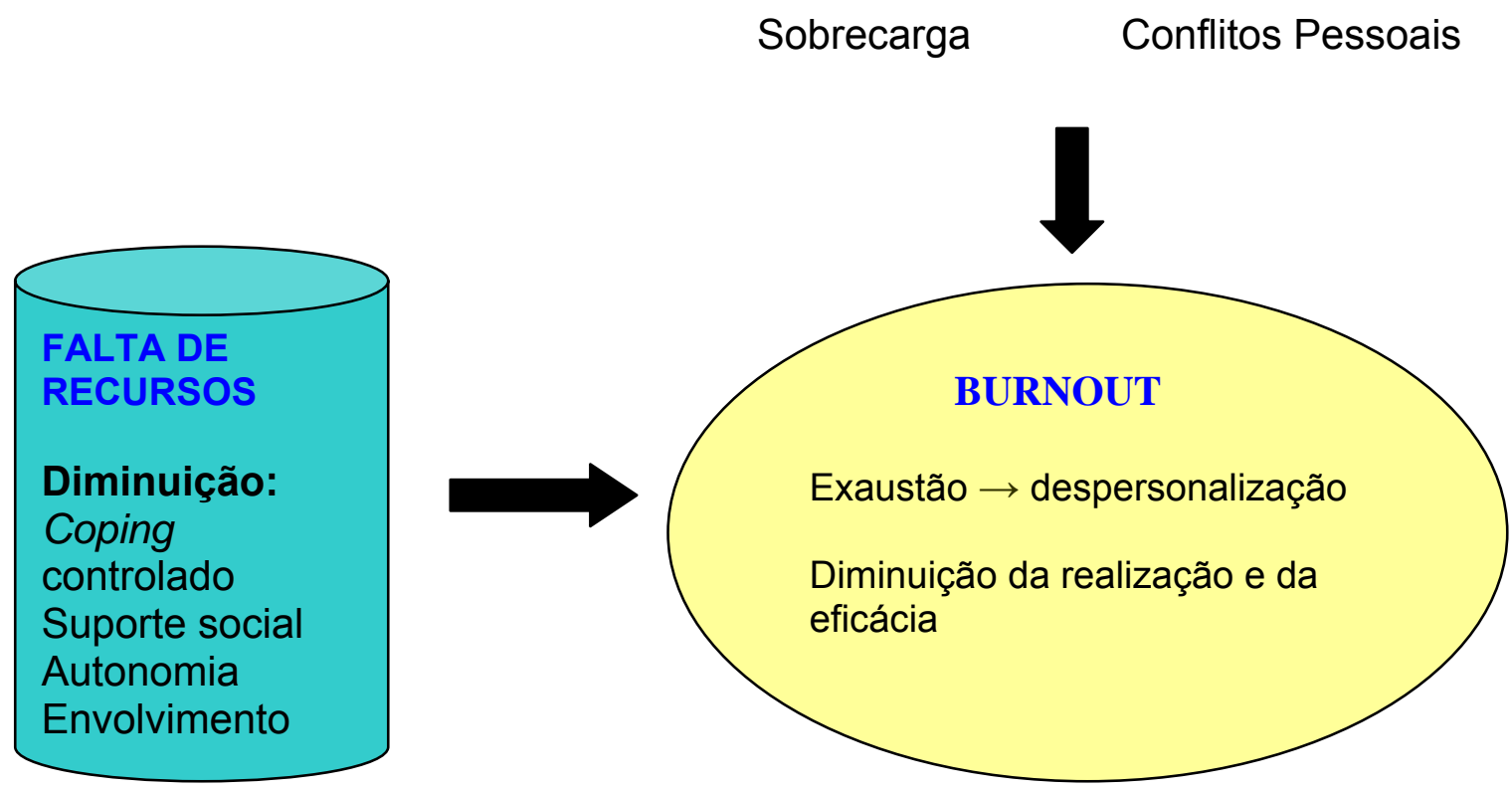

Custos

Comprometimento organizacional diminuído

Rotatividade

Absenteísmo

Doença

Fonte: Manual MBI, 1996 


\subsubsection{Dados Quantitativos}

SCHAUFELI e ENZMANN (1998) divulgaram quais as profissões e campos ocupacionais de mais elevada ocorrência da síndrome, após avaliarem 473 estudos publicados e 538 dissertações ou teses, que utilizaram o maslach burnout invetory (MBI) para pesquisar esgotamento, entre 1978 e 1996. Os profissionais da saúde apresentaram maior taxa $(33,8 \%)$, seguido pelos profissionais do ensino e educação $(26,6 \%)$, trabalho social $(7 \%)$, de administração $(3,7 \%)$, polícia e sistema corretivo $(3,4 \%)$ e sem especificação ou outras profissões $(25,7 \%)$.

Entre os profissionais de saúde, vários autores idetificaram os médicos e os enfermeiros como população de risco para desenvolvimento da síndrome. Nesse sentido HERNÁNDEZ (2003) avaliou médicos e enfermeiros da atenção primária e secundária $(\mathrm{N}=287)$, e verificou maior prevalência nos trabalhadores da atenção primária $(43,8 \%)$. Na atenção secundária, a prevalência entre os enfermeiros foi de $20,65 \%$ e em médicos 25\%. GRUNFELD (2000) e col. estudaram profissionais de serviços de oncologia em Ontário ( $N=681)$, e identificaram que os médicos foram os profissionais que apresentaram maiores taxas de exaustão emocional $(53,3 \%)$ e despersonalização $(22,1 \%)$.

No Brasil, CARVALHO (1995), ao estudar professores da rede estadual de ensino do $1^{\circ}$ e $2^{\circ}$ graus, de sete municípios de São Paulo, observou níveis 
elevados de exaustão, despersonalização e decepção, respectivamente, $17,7 \%, 19,7 \%$ e $22 \%$. TAMAYO (1997) descreveu os níveis de esgotamento de auxiliares de enfermagem e enfermeiras, de dois hospitais em Brasília, identificando a síndrome em $16,15 \%$ da amostra estudada ( $N=$ 229).

\subsubsection{Fatores Precipitantes}

Pode-se agrupar as variáveis associadas à síndrome do esgotamento em três categorias (CORDES e DOUGHERTY, 1993):

1. Características do cargo: sobrecarga de trabalho, ambigüidade de papel e conflitos.

MASLACH e GOLDBERG, (1998), SPICKARD e col.(2002) concordam que a sobrecarga de trabalho é uma das características mais correlacionadas aos altos níveis de esgotamento. Os conflitos interpessoais entre colegas de trabalho são citados como estressores mais do que a relação com os clientes (SHINN e col, 1984). Como demonstraram PICK e LEITER (1991) em um estudo com enfermeiras identificaram que a maioria delas considerava o esgotamento resultado dos conflitos entre colegas.

2. Características organizacionais: contingências de recompensas e punições. 
Reconhecimento insuficiente, falta de apoio social, falta de justiça e conflito de valores são fatores de risco organizacionais também na opinião de MASLACH (2005).

3. Características pessoais: idade, sexo, tempo de trabalho, suporte social.

Com relação aos fatores pessoais, MASLACH e JACKSON (1981) afirmam que a idade tende a ter relação com esgotamento, entre os empregados mais jovens os níveis de esgotamento são mais altos do que nos indivíduos acima de 30 ou 40 anos, mas a idade se confunde com a experiência de trabalho, de modo que parece haver um risco maior no início da carreira. Uma pequena diferença, porém consistente, entre os sexos é que os homens possuem maior desumanização e as mulheres maior exaustão, mas esses resultados podem refletir a confusão entre os fatores sexo e ocupação. Os indivíduos solteiros apresentam níveis maiores de esgotamento quando comparados com casados e divorciados. Quanto a diferença entre os grupos étnicos, poucos estudos avaliam esta variável, não sendo evidente diferenças significativas (MASLACH, 2005).

Uma maior freqüência foi verificada em indivíduos mais velhos (acima de 55 anos), solteiros, etilistas, sedentários, obesos, com história de doença física ou mental. Não houve diferenças relacionadas ao sexo, em estudo com 3270 trabalhadores finlandeses realizado por ALOHA e col. (2006). TAMAYO (1997) observou maiores taxa de esgotamento nos auxiliares de 
enfermagem e enfermeiras da faixa etária de 25 a 29 anos, solteiros e com tempo de serviço entre zero e 5 anos.

Como mencionado anteriormente, os profissionais dos serviços de saúde são mais afetados pelo esgotamento. Na opinião de DELGADO (1993), isso se justifica por possuírem uma filosofia humanística em seu trabalho e se defrontarem com um sistema de saúde geralmente desumanizado e despersonalizado, ao qual têm que se adaptar. Além disso, estão submetidos a uma grande demanda emocional, condição identificada como maior contribuidor para o esgotamento, especialmente quando o cliente tem dor, angústia, ou raiva (CHERNISS, 1992). Dois tipos de pessoas estão especialmente expostas ao esgotameto, as dinâmicas e propensas a assumir papéis de liderança ou de grande responsabilidade e as idealistas que colocam grande empenho em alcançar metas frequentemente impossíveis de serem atingidas, exigindo muito de si mesmas. O fator desencadeante mais freqüente seria uma situação de sobrecarga ou de frustração no trabalho (MENDES, 2003).

Três pilares estariam presentes na determinação da síndrome, segundo MASLACH e LEITER (1997): uma forte motivação inicial que é uma condição necessária para o desenvolvimento do esgotamento; estar associado a um ambiente de trabalho desfavorável e a autoperpetuação devido ao uso de estratégias inadequadas de coping, definido por FOLKMAN e col. (1986) como esforços cognitivos e comportamentais que se desenvolvem para responder às demandas específicas externas e/ou 
internas avaliadas como excessivas para os recursos do indivíduo. Assim, os indivíduos com esgotamento lidam com eventos estressantes de forma passiva e defensiva.

Todos os fatores de insegurança social e econômica aumentam o risco de esgotamento profissional em todas as faixas etárias (SCHAUFELI e ENZMANN,1998), assim como, fatores ambientais, particularmente as características do trabalho, são mais relacionados a altos níveis de esgotamento do que fatores pessoais, demográficos e variáveis de personalidade. Nesse sentido, MASLACH e LEITER (1997) defendem que a síndrome não é um problema do indivíduo, mas sim de seu contexto de trabalho.

\subsubsection{Fatores de proteção}

Para MASLACH (2005), a forma como as pessoas reagem ao estresse (coping) está associada ao risco de esgotamento. Assim, os indivíduos que possuem estilo de coping ativo e confrontador, executam ações e reavaliações cognitivas de enfrentamento, que são denominadas estratégias de controle, e apresentam menos esgotamento. Enquanto, os sujeitos que lidam com eventos estressantes de forma passiva, defensiva, desenvolvem estratégias de esquiva e possuem maior chance de esgotamento. 
As mudanças organizacionais são consideradas condições básicas para reduzir a suscetibilidade ao esgotamento, ações que promovam maior autonomia, suporte organizacional, participação nas políticas organizacionais e interesse pelo trabalho (CHERNISS,1992; RIJK e col.,1998; MASLACH, 2005).

Outro fator de proteção destacado na literatura é o suporte social fornecido pelos colegas de trabalho, o que se relaciona com maior realização pessoal. Do mesmo modo que o apoio dos membros da família melhoram a capacidade de lidar com as demandas emocionais, reduzindo a possibilidade de esgotamento (PICK e LEITER, 1991).

Na opinião dos profissionais da atenção primária (médicos, enfermeiros e auxiliares de enfermagem) entrevistados por MARTíN e col.(2001) os fatores que contribuiriam para evitar o esgotamento são: a diminuição do número de atendimentos, maior investimento em cursos de formação, desenvolvimento da carreira profissional e melhoria nas relações entre os níveis de assistência. Nesse sentido, GLASBERG e col. (2007), descrevem que os oncologistas brasileiros consideram como as principais medidas para prevenir a síndrome do esgotamento: a limitação do número de pacientes atendidos por dia, melhora da relação com as companhias de seguro, aumento de salários e possibilidade de crescimento na carreira. 
A abordagem da prevenção da síndrome é feita por MASLACH e LEITER (1997) e SPICKARD e col. (2002), que defendem a idéia de que a melhor maneira de prevenir o esgotamento é promover o bem-estar pessoal e profissional em todos os níveis: físico, emocional e psicológico, sendo a prevenção responsabilidade dos sistemas de saúde e das instituições onde os profissionais trabalham.

\subsubsection{Conseqüências para o trabalhador e para as organizações}

O esgotamento está associado a importantes perdas de recursos humanos e econômicos, uma vez que compromete o bem-estar físico e psicológico, promove diminuição da qualidade do trabalho, queda da criatividade, da produtividade e do comprometimento organizacional, absenteísmo, alta rotatividade, uso abusivo de tranqüilizantes, álcool e outras drogas, afetando também as relações familiares e sociais do trabalhador (MASLACH e LEITER, 1997; DELGADO, 1993; TAMAYO e TRÓCCOLI, 2002). SCHAUFELI e BUUNK (1996) acrescentam outras conseqüências: atrasos, acidentes, negligência e erros no trabalho.

A necessidade da conscientização de pesquisadores, órgãos públicos e serviços clínicos com relação ao fenômeno do esgotamento é destacada por DELGADO (1993), identificando a importância de aprofundar os estudos sobre prevenção. 


\subsection{TRANSTORNO MENTAL COMUM}

A expressão transtorno mental comum (TMC) foi criada por GOLDBERG e HUXLEY (1992), e está relacionada à presença de sintomas como insônia, fadiga, irritabilidade, esquecimento, dificuldade de concentração e queixas somáticas, com intensidade ainda insuficiente para caracterizar um transtorno mental específico. São também denominados de doenças mentais comuns ou transtornos psiquiátricos menores e, de acordo com a Classificação Internacional das Doenças os TMC incluem os transtornos depressivos, ansiosos, somatoformes e neuróticos (WHO, 1992).

Do mesmo modo que o esgotamento profissional, os TMC são causas importantes de dias perdidos de trabalho, de incapacitação, da elevação da demanda dos serviços de saúde, gerando alto custo social, econômico e individual (LIMA e col., 1996; GOLDBERG e HUXLEY,1992).

Com relação à prevalência, PATEL e KLEINMAN (2003) publicaram em boletim da WHO levantamento de pesquisas populacionais realizadas em países da África, Ásia e América Latina, desde 1990, e observaram que as prevalências de TMC variaram entre 20 e $30 \%$. Os fatores de risco para TMC descritos em estudos brasileiros incluem: gênero feminino, baixa escolaridade, renda, ocupação, desemprego, posse de bens duráveis e condições de moradia (COUTINHO e col., 1996; LIMA e col,1996; LUDERMIR e MELO FILHO, 2002). 
Nos últimos anos, surgiu a discussão sobre o significado da associação da síndrome do esgotamento profissional à morbidade psiquiátrica. A hipótese de que o esgotamento não seria um precursor da depressão, mas uma forma de doença mental, foi levantada por MASLACH (2005).

Segundo ALUJA (1997), depressão, ansiedade e os transtornos somatoformes são considerados as principais respostas psicológicas à síndrome do esgotamento. Outros autores consideram o esgotamento fator preditor de morbidade psiquiátrica (GRAHAM e col., 1996; MASLACH, 2005).

Também está descrito que uma das dimensões do esgotamento, a exaustão emocional, pode comprometer a saúde mental e física dos trabalhadores, e deteriorar a qualidade de vida no trabalho e o funcionamento da organização (WRIGHT e CROPANZANO, 1998).

Em Londres, médicos, enfermeiras e outros membros das equipes multiprofissionais que trabalhavam no modelo tradicional à saúde mental e no modelo de assistência baseado na comunidade, foram estudados por PROSSER e col. (1999), utilizando o general health questionnaire (GHQ12), que identifica indivíduos com alta probabilidade de ter morbidade psiquiátrica, e o $\mathrm{MBI}$, para esgotamento. Não foram evidenciadas 
associações estatisticamente significativas entre as dimensões do esgotamento e transtorno mental.

Por outro lado, McMANUS e col. (2002) pesquisaram médicos do Reino Unido ( $\mathrm{N}=331$ ), também utilizando o $\mathrm{MBI}$ e o $\mathrm{GHQ}-12$, e observaram associação entre escores elevados no GHQ-12 e níveis altos de exaustão emocional e decepção. 


\section{JUSTIFICATIVA}

Os ACS estão submetidos a uma dinâmica de trabalho diferenciada dos demais componentes da ESF, pois residem na área que é alvo das intervenções. Muitas vezes, esses profissionais enfrentam na sua microárea situações de difícil resolução (por exemplo, famílias em condições socioeconômicas precárias, violência, tráfico de drogas), sem uma rede social instituída e sem a equipe interdisciplinar necessária para discussão e elaboração das ações que possam modificar as dificuldades reconhecidas. Assim, os ACS podem estar sujeitos a um alto risco de desenvolver a síndrome do esgotamento profissional e/ou os transtornos mentais comuns. A investigação destes prováveis problemas de saúde possivelmente relacionados à atividade profissional dos ACS pode orientar a elaboração de intervenções visando melhorar a condição laboral dos ACS e diminuir o risco de esgotamento profissional e oferecer os cuidados necessários aos ACS que apresentam tais problemas. 


\section{OBJETIVOS}

1. Investigar a ocorrência de esgotamento profissional em ACS do município de São Paulo.

2. Investigar se características dos ACS e de suas atividades estão associadas ao esgotamento profissional.

3. Estimar a prevalência de transtornos mentais comuns em ACS.

4. Investigar a associação entre esgotamento profissional e transtornos mentais comuns em ACS. 


\section{MÉTODO}

\subsection{DESENHO E AMOSTRA}

Esta pesquisa é um estudo de corte transversal, cuja população alvo foi constituída pelos ACS de seis unidades básicas de saúde (UBS) vinculadas à Fundação Faculdade de Medicina da Universidade de São Paulo e situadas nos bairros Lapa, Pinheiros e Butantã - Coordenadoria de Saúde Centro-Oeste: UBS Parque da Lapa, Manoel Joaquim Pêra, Vila Jaguará, Vila Piauí, Boa Vista e São Jorge. As unidades Boa Vista, Parque da Lapa, Pêra e Vila Piauí são constituídas exclusivamente por equipes de PSF. As unidades São Jorge e Boa Vista são campos de estágio para alunos da Escola de Enfermagem e Faculdade de Medicina da USP, com a participação dos ACS na maior parte das atividades acadêmicas. A UBS Parque da Lapa recebe alunos de enfermagem da Faculdade de Enfermagem São Camilo. As 6 UBS foram escolhidas para o estudo pela facilidade de acesso às mesmas e correspondem a 40\% das UBS da região Centro-Oeste que possuem equipes de PSF. Por se tratar de estudo exploratório não foi feito cálculo do tamanho da amostra.

Segundo o censo de 2000, a área das Subprefeituras Lapa, Pinheiros e Butantã (figura 6) possuia uma população de 945.993 habitantes. Essa área apresenta características heterogêneas no que se refere aos indicadores socioeconômicos, como o Índice de Envelhecimento (Lapa 
67,0; Pinheiros 110,9; Butantã 26,2) e o Índice de Desenvolvimento Humano (IDH). O IDH é adotado desde 1990 pelo Programa das Nações Unidas para o Desenvolvimento Humano para aferir o nível de desenvolvimento econômico e social, sendo constituído por três componentes básicos: renda, longevidade e educação. É considerado elevando acima de 0,80, médio entre 0,50 e 0,79 e baixo se menor ou igual a 0,49 . Das seis UBS estudadas, 5 estão localizadas nas subprefeituras do Butantã e da Lapa, que apresentam IDH variando entre 0,52 a 0,81 e 0,52 a 0,78 , respectivamente; Pinheiros possui níveis mais elevados $(0,68$ a 0,84). Entretanto, aquelas cinco unidades situam-se nos bairros com os menores IDH da região, entre 0,52 e 0,62, estando aquém do índice municipal $(0,84)$.

Foram considerados elegíveis todos os ACS que estivessem trabalhando há pelo menos 6 meses nas referidas UBS por ocasião do início do estudo, em junho de 2006. 
FIGURA 6. Mapa das Subprefeituras e distritos do município de São Paulo

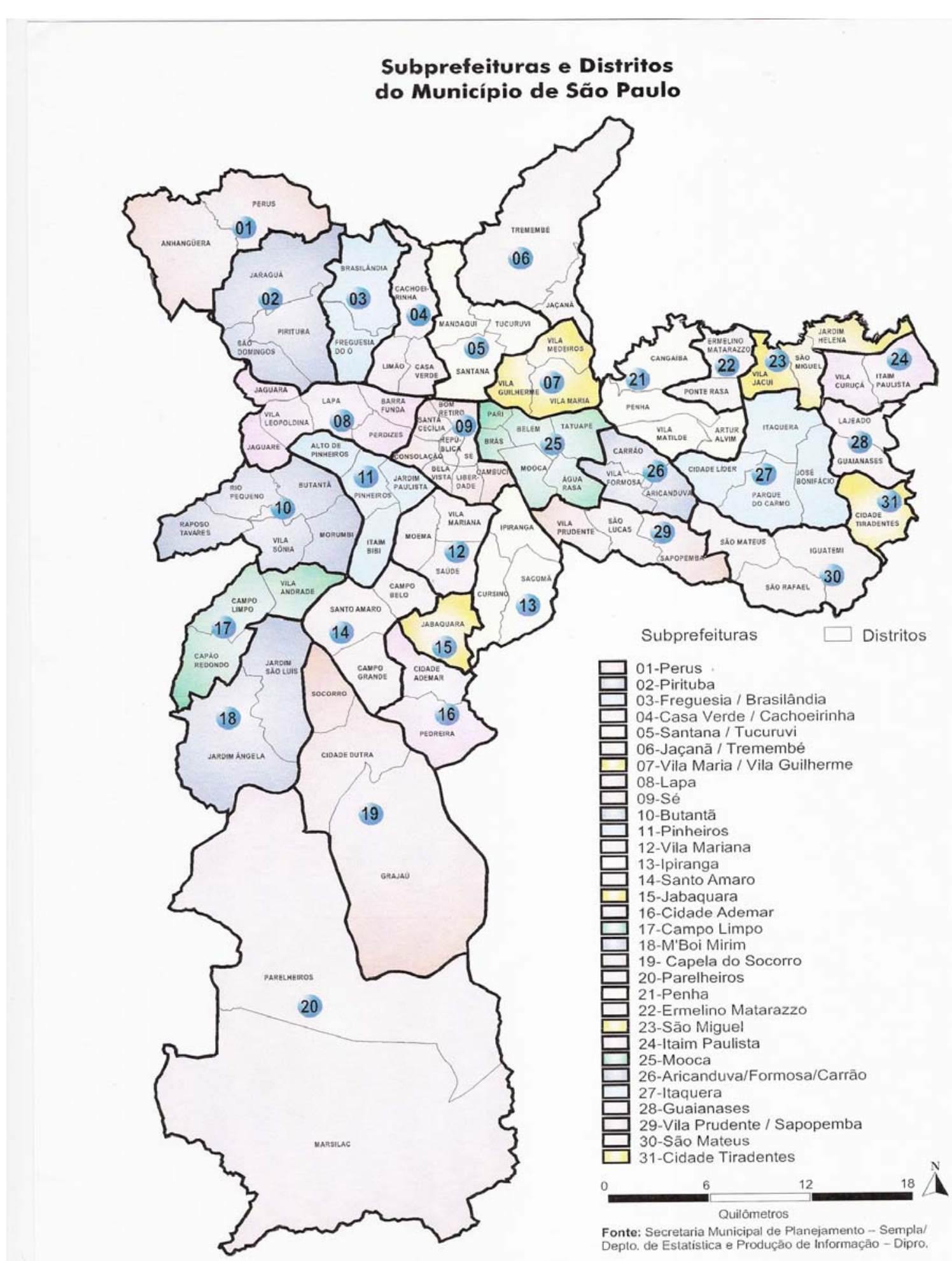

Fonte: Prefitura de São Paulo. Secretaria Municipal de Planejamento (2007). 


\subsection{INSTRUMENTOS}

\subsubsection{QUESTIONÁRIO COM OS DADOS: SOCIODEMOGRÁFICOS, RELACIONADOS AO TRABALHO E À SAÚDE DO ENTREVISTADO}

Este questionário foi composto por perguntas relacionadas às características socio-demográficas e socio-econômicas (nome, idade, estado civil, cor, escolaridade, religião, renda familiar mensal, número de pessoas mora na residência, número de cômodos, há quanto tempo mora na área), aspectos relacionados ao trabalho (tempo de trabalho como ACS, participação em programa de capacitação, faltas no trabalho nos últimos trinta dias, se há algum aspecto relacionado ao esgotamento profissional na opinião do entrevistado), se a microárea tem favela, cortiço ou área de invasão (microárea de risco) e uso atual de medicação (calmante, tranqüilizante ou antidepressivo).

\subsubsection{SELF REPORTING QUESTIONNAIRE}

A elaboração do Self Reporting Questionnaire (SRQ-20) (HARDING e col., 1980) foi coordenada pela Organização Mundial de Saúde, tendo como meta desenvolver um instrumento que rastreasse possíveis casos de transtorno mental em serviços de atenção primária e na comunidade, principalmente em países em desenvolvimento (WHO, 1994). 
O questionário é composto por vinte questões, cada uma com respostas tipo binário (sim ou não), sobre sintomas emocionais e físicos associados a quadros psiquiátricos, como nervosismo, cansaço, cefaléias freqüentes, insônia, alteração do apetite, sentimentos de tristeza, desesperança e piora da concentração. A cada questão deve ser atribuído o valor 1 quando a resposta é sim e zero quando a resposta é não, tomando-se como referência os últimos trinta dias. Pode ser auto-aplicado ou administrado por entrevistador, sendo que apenas uma das estratégias deve ser utilizada em uma investigação.

O SRQ-20 foi validado em diversos estudos internacionais e nacionais, com sensibilidade variando de 63 a 90\% e, especificidade de 44 a 95\% (WHO, 1994). Em estudo realizado no Brasil, MARI e WILLIANS (1986) estabeleceram o ponto de corte $7 / 8$ como aquele que reunia melhores valores de sensibilidade e especificidade, respectivamente, $83 \%$ e $80 \%$, quando analisado pela Relative Operating Characteristics Curve (ROC), com área igual a 0,90.

\subsubsection{MASLACH BURNOUT INVENTORY}

Este instrumento (anexo 3) foi desenvolvido por MASLACH e JACKSON (1981) e tem sido utilizado para medir o grau de esgotamento em que se encontra o profissional. $\mathrm{O}$ instrumento possui três seções: exaustão emocional; despersonalização (ceticismo); reduzida realização pessoal 
(decepção). Para cada item pergunta-se a freqüência com que o entrevistado percebe ou vivencia determinado sentimento ou atitude. As respostas são escalonadas como: nunca (0); algumas vezes ao ano (1); no máximo uma vez por mês (2); algumas vezes ao mês (3); uma vez por semana (4); poucas vezes por semana (5); e diariamente (6).

São calculados escores para cada uma das três subescalas e pontos de corte são utilizados para classificar cada dimensão em níveis alto, médio ou baixo de esgotamento, como descrito a seguir:

$\begin{array}{cl}\text { SUBESCALA } & \text { PONTOS } \\ \text { Exaustão emocional } & \text { Alta } 27 \text { ou acima } \\ & \text { Moderada } 17-26 \\ & \text { Baixa } 0-16 \\ \text { Despersonalização } & \text { Alta } 13 \text { ou acima } \\ & \text { Moderada } 7-12 \\ & \text { Baixa } 0 \text { - 6 } \\ \text { Reduzida Realização Pessoal } & \text { Alta 0 - 31 } \\ \text { (decepção) } & \text { Moderada 32-38 } \\ & \text { Baixa } 39 \text { ou acima }\end{array}$


É importante salientar, que os escores da subescala decepção seguem uma direção contrária aos das outras subescalas. Assim, para classificar decepção como alta o escore deve estar na faixa de zero a 31 .

A combinação dos níveis de exaustão, despersonalização e decepção define o grau da síndrome do esgotamento. Desse modo, de acordo com MASLACH e JACKSON (1981), considera-se um indivíduo com síndrome de esgotamento alta quando escores obtidos nas três subescalas são altos, o esgotamento moderado é constatado quando há escores moderados nas três subescalas, e por fim, existe esgotamento profissional baixo na obtenção de escores baixos nas três dimensões. No entanto, cabe ressaltar, que esse critério faz com que muitos sujeitos não sejam classificados, por esse motivo outros autores (GRUNFELD e col., 2000) propõem outra maneira para interpretar os resultados do $\mathrm{MBI}$, considerando que o esgotamento está presente quando pelo menos uma das dimensões atinge escore alto. No presente estudo utilizamos o critério daquelas autoras para análise das variáveis de exposição e de desfecho, uma vez que é o mais utilizado na literatura mundial.

No Brasil, o MBI foi validado por CARVALHO (1995), estudando a síndrome do esgotamento em professores da rede do ensino público oficial de primeiro e segundo graus. A análise fatorial foi escolhida como procedimento estatístico para testar a validade da escala, esta também foi testada pela correlação com critérios externos, uma das formas indicadas 
por MASLACH e JACKSON (1981). O coeficiente alfa de Cronbach foi usado para verificação da confiabilidade. Foram calculadas para cada indivíduo as médias dos escores fatoriais. A diferença das médias foi testada através do modelo de análise de variância One Way, para verificar a associação com a síndrome de burnout.

TAMAYO (1997) também validou o MBI no Brasil, utilizando o procedimento metodológico que incluiu tradução da versão original para o português, tradução reversa feita por três pesquisadores, adaptação semântica e validação semântica. A análise fatorial do inventário foi realizada com uma amostra de 277 enfermeiras e auxiliares de enfermagem de dois hospitais em Brasília. Também foi utilizado o alpha de Cronbach. Os resultados confirmaram 19 itens distribuídos em 3 fatores com eigenvalue superior a 1,4 , conceitualmente relacionado a exaustão emocional (fator $01 ; 10$ itens; alpha=0.82), Diminuição da Realização pessoal (fator 02; 7 itens; alpha=0,67) e despersonalização (fator 03; 2 itens; alpha 0,69). Para todos os fatores foi considerado o critério de carga fatorial $>0,3$.

\subsubsection{DADOS DO SISTEMA DE INFORMAÇÃO DA ATENÇÃO BÁSICA (SIAB)}

O SIAB é considerado o principal instrumento de monitoramento das ações do PSF, foi implantado nacionalmente em 1998, é atualizado mensalmente e fornece informações sobre cadastros de famílias, características da 
população da microárea, condições de moradia e saneamento, situação de saúde, além de dados sobre produção e composição das ESF.

O relatório mais recente do SIAB de cada microárea foi solicitado aos gerentes das UBS. Foram utilizados para esta pesquisa os seguintes dados: número de pessoas cadastradas por microárea; proporção de indivíduos com até 14 anos, proporção de pessoas com plano de saúde, destino do lixo (coleta pública, queimado ou céu aberto) e do esgoto (sistema de esgoto, fossa ou céu aberto). Essas informações foram escolhidas por fornecerem elementos para a análise de riscos para a saúde associados a fatores ambientais e indicarem as características socioeconômicas da população cadastrada nas microáreas (OPAS, 2002), o que poderia está relacionado à carga de tarbalho a que o ACS estaria exposto, podendo haver associação dessas informações do SIAB com o esgotamento profissional e com o TMC.

\subsection{PROCEDIMENTOS}

\subsubsection{PRÉ-TESTE:}

Segundo ARMSTRONG e col. (1992), o pré-teste é essencial para o desenvolvimento de qualquer questionário e tem o objetivo de identificar questões de difícil interpretação, ambíguas ou que suscitem respostas indesejáveis. Esse autor postula que o pré-teste permite verificar se 
existem palavras que são mal compreendidas, se as perguntas são interpretadas do mesmo modo por todos os entrevistados, se cada questão fechada tem uma resposta aplicável para cada participante, se existe algum item que não é respondido e se alguma pergunta suscita respostas não interpretáveis. O pré-teste foi realizado na UBS Vila Dalva, localizada no Butantã, também vinculada à Fundação Faculdade de Medicina e à Coordenadoria de Saúde Centro-Oeste. Foram entrevistados 23 ACS. A partir do pré-teste, foram feitas as adaptações necessárias nos instrumentos. O pré-teste também permitiu ter idéia do tempo necessário para cada entrevista, em média 20 minutos, possibilitando elaborar um cronograma mais preciso para realização das entrevistas.

\subsubsection{PESQUISA DE CAMPO}

Todos os ACS que preenchiam o critério de inclusão nas seis UBS escolhidas foram convidados a participar do estudo. Os questionários foram aplicados por um mesmo entrevistador, individualmente, em espaço reservado para garantir privacidade. As entrevistas foram agendadas de acordo com a disponibilidade dos participantes. O período de realização do trabalho de campo foi de 19/06/2006 a 25/10/2006. 


\subsection{ANÁLISE DOS DADOS}

Os dados foram digitados em planilha eletrônica utilizando o programa Epidata 3.0 (Epidata Association, 2002). Foi realizada digitação dupla, para reduzir erros de digitação. A análise estatística foi feita com o programa STATA 8.0 (Stata Corporation, 2003).

\subsubsection{Variáveis de Desfecho:}

1. Presença de transtorno mental comum (caso), definido por escore igual ou maior que 8 obtido na aplicação do SRQ-20;

2. Presença de exaustão emocional níveis moderado e alto;

3. Presença de despersonalização níveis moderado e alto;

4. Presença de decepção (redução da realização pessoal) nível alto.

\subsubsection{Variáveis de Exposição:}

As variáveis de exposição foram categorizadas, conforme os quadros 1, 2 e 3 abaixo. Outras duas variáveis consideradas foram o uso atual de medicação calmante, tranqüilizante ou antidepressivo (sim ou não) e a existência de aspecto relacionado ao esgotamento profissional na opinião do agente comunitário (sim ou não). 
QUADRO 1: Variáveis sociodemográficas incluídas na análise.

\begin{tabular}{|c|c|}
\hline Variável & Categorias \\
\hline Sexo & $\begin{array}{l}\text { Masculino } \\
\text { Feminino }\end{array}$ \\
\hline Idade & $\begin{array}{l}\text { Até } 30 \text { anos } \\
31 \text { a } 40 \text { anos } \\
41 \text { a } 50 \text { anos } \\
\text { Mais de } 50 \text { anos }\end{array}$ \\
\hline Cor (auto-referida) & $\begin{array}{l}\text { Branca } \\
\text { Parda } \\
\text { Negra } \\
\text { Outra }\end{array}$ \\
\hline Estado civil & $\begin{array}{l}\text { Casado/mora junto } \\
\text { Solteiro } \\
\text { Viúvo/separado }\end{array}$ \\
\hline Religião & $\begin{array}{l}\text { Católica } \\
\text { Evangélica } \\
\text { Outra }\end{array}$ \\
\hline \multirow[t]{2}{*}{ Escolaridade } & $\begin{array}{l}\text { Ensino fundamental/médio } \\
\text { Outro (curso técnico) }\end{array}$ \\
\hline & Superior incompleto/completo \\
\hline \multirow[t]{2}{*}{$\begin{array}{l}\text { Renda familiar (em salários } \\
\text { mínimos) }\end{array}$} & $\begin{array}{l}\text { De } 2 \text { a } 3 \text { salários mínimos } \\
\text { De } 4 \text { a } 5 \text { salários mínimos } \\
\text { De } 6 \text { a } 7 \text { salários mínimos }\end{array}$ \\
\hline & Mais de 7 salários mínimos \\
\hline \multirow{2}{*}{$\begin{array}{l}\text { Pessoas morando com o } \\
\text { indivíduo }\end{array}$} & Nenhuma ou uma pessoa \\
\hline & $\begin{array}{l}2 \text { pessoas } \\
3 \text { pessoas } \\
4 \text { pessoas } \\
\text { Mais de } 4 \text { pessoas }\end{array}$ \\
\hline Cômodos na residência & $\begin{array}{l}\text { Até } 2 \text { cômodos } \\
3 \text { cômodos } \\
4 \text { cômodos } \\
5 \text { cômodos } \\
\text { Mais de } 5 \text { cômodos }\end{array}$ \\
\hline $\begin{array}{l}\text { Aglomeração domiciliar } \\
\text { (número de pessoas/ número } \\
\text { de cômodos) }\end{array}$ & $\begin{array}{l}\leq 0,75 \\
0,76-1,0 \\
\geq 1,01\end{array}$ \\
\hline
\end{tabular}


QUADRO 2: Variáveis relacionadas às características do trabalho incluídas a análise.

\begin{tabular}{|c|c|}
\hline Variável & Categoria \\
\hline \multirow[t]{2}{*}{ Tempo de trabalho (meses)* } & $\leq 42$ meses \\
\hline & $>42$ meses \\
\hline \multirow[t]{2}{*}{ Curso de capacitação } & Sim \\
\hline & Não \\
\hline \multirow[t]{3}{*}{ Faltas no trabalho } & Nenhuma falta \\
\hline & Uma falta \\
\hline & Duas ou mais faltas \\
\hline \multirow[t]{2}{*}{ Aspecto de esgotamento adicional } & Não \\
\hline & Sim \\
\hline \multirow[t]{6}{*}{ Qual aspecto de esgotamento (outros) } & Relação com equipe PSF+UBS \\
\hline & Relação com a comunidade \\
\hline & SIAB \\
\hline & Dificuldade nos serviços de \\
\hline & referência \\
\hline & Outros \\
\hline \multirow[t]{2}{*}{ Microárea de risco } & SIM \\
\hline & NÃO \\
\hline
\end{tabular}

*estratificação feita de acordo com a mediana 
QUADRO 3: Variáveis relacionadas às características da microárea, de acordo com dados do sistema de informação em atenção básica (SIAB) que entraram na análise.

\begin{tabular}{ll}
\hline \multicolumn{1}{c}{ Variável } & Categoria \\
\hline & \\
Pessoas cadastradas* & $\leq 530$ pessoas \\
& $>530$ pessoas \\
Populaçãosde 14 anos* $^{*}$ & $\leq 20 \%$ \\
& $>20 \%$ \\
Destino lixo & Coleta pública \\
& Lixo queimado \\
& Céu aberto \\
& \\
Destino esgoto & Esgoto público \\
& Fossa \\
& Céu aberto \\
Pessoas com plano de saúde* & \\
& $>20 \%$ \\
\hline
\end{tabular}

*As estratificações foram feitas de acordo com a mediana

As associações das variáveis de desfecho com as variáveis de exposição foram avaliadas através dos odds ratios (OR) simples e ajustado, com intervalos de confiança de $95 \%$. Valores de $\mathbf{p}$ foram obtidos com o teste de Wald. A regressão logística foi utilizada para obter as estimativas de OR e os valores de p. A construção dos modelos de regressão logística foi feita pelo método stepwise forward, no qual a variável com maior associação estatística é introduzida inicialmente, seguida pela outras variáveis, de acordo com a ordem decrescente da associação estatística encontrada na análise univariada (KATZ, 2003). O critério de inclusão de variáveis nos 
modelos múltiplos foi o valor de $\mathbf{p}$ obtido na análise univariada $\leq 0,20$. Em seguida, as variáveis selecionadas foram testadas uma a uma no modelo múltiplo e somente aquelas que permaneceram significativas foram mantidas $(p \leq 0,05)$. 


\section{CONSIDERAÇÕES ÉTICAS}

Este projeto foi aprovado pelas comissões de ética da Faculdade de Medicina da Universidade de São Paulo e da Secretaria Municipal de Saúde de São Paulo. Inicialmente, entramos em contato com os gerentes das unidades envolvidas e solicitamos autorização para a inclusão da unidade na pesquisa. Após a anuência do gerente, os ACS foram informados sobre os objetivos e procedimento deste estudo e convidados a participar. Aqueles que concordaram em participar assinaram o termo de consentimento livre e esclarecido. Quando os participantes solicitaram acompanhamento por profissional da área de saúde mental, foram encaminhados para um serviço de referência.

A autorização do uso do maslach burnout inventory e o manual de instruções para aplicação da entrevista foram adquiridos na IDH (Instrumentos de Desenvolvimento Humano Ltda), empresa que representa os direitos da autora do questionário no Brasil. 


\section{RESULTADOS}

\subsection{CARACTERÍSTICAS DOS SUJEITOS}

Houve boa aceitação da pesquisa pelos participantes, já que do total de 143 ACS elegíveis, 141 concordaram em participar do estudo. A tabela 1 mostra a distribuição dos entrevistados segundo a UBS em que trabalhavam.

Tabela 1 - Distribuição dos participantes de acordo com as Unidades Básicas de Saúde, São Paulo (N=141).

\begin{tabular}{lcc}
\hline Unidade Básica de Saúde & N & $\%$ \\
\hline & & \\
Boa Vista & 29 & 20,6 \\
Pq.Lapa & 30 & 21,3 \\
Pêra & 12 & 8,5 \\
São Jorge & 32 & 22,7 \\
Vila Jaguará & 18 & 12,8 \\
Vila Piauí & 20 & 14,2 \\
\hline
\end{tabular}

A média de idade foi de 38,9 anos, sendo a faixa etária dos indivíduos entre 31 a 40 anos a mais encontrada. Vinte (14,2\%) participantes referiram ter realizado algum curso técnico e $18(12,7 \%)$ tinham curso superior incompleto ou completo. Observamos um amplo predomínio de mulheres (92,2\%). A aglomeração domiciliar (número de pessoas por cômodo) mais observada foi de 0,76 a $1,0(36,9 \%)$ e mais da metade dos entrevistados possuíam renda familiar mensal de 4 salários mínimos ou mais (58,9\%) (tabela 2$)$. 
Tabela 2 - Distribuição dos entrevistados segundo as características sociodemográficas e socioeconômicas, São Paulo ( $N=141)$.

\begin{tabular}{|c|c|c|c|}
\hline Variável & Categoria & $\mathbf{N}$ & $\%$ \\
\hline \multirow{2}{*}{ Sexo } & Masculino & 11 & 7,8 \\
\hline & Feminino & 130 & 92,2 \\
\hline \multirow{4}{*}{ Idade } & Até 30 anos & 35 & 28,8 \\
\hline & 31 a 40 anos & 47 & 33,3 \\
\hline & 41 a 50 anos & 34 & 24,1 \\
\hline & Mais de 50 anos & 25 & 17,7 \\
\hline \multirow{4}{*}{ Cor (auto-referida) } & Branca & 58 & 41,1 \\
\hline & Parda & 49 & 34,8 \\
\hline & Negra & 23 & 16,3 \\
\hline & Outra & 11 & 7,8 \\
\hline \multirow{3}{*}{ Estado civil } & Casado/mora junto & 78 & 55,4 \\
\hline & Solteiro & 41 & 29,1 \\
\hline & Viúvo/separado & 22 & 15,6 \\
\hline \multirow{3}{*}{ Religião } & Católica & 72 & 51,1 \\
\hline & Evangélica & 37 & 26,2 \\
\hline & Outra & 32 & 22,7 \\
\hline \multirow{3}{*}{ Escolaridade } & Ensino fundamental/médio & 103 & 73,0 \\
\hline & Outro (curso técnico) & 20 & 14,2 \\
\hline & Superior incompleto/completo & 18 & 12,7 \\
\hline \multirow{3}{*}{$\begin{array}{l}\text { Renda familiar (em } \\
\text { salários mínimos) }\end{array}$} & De 2 a 3 salários mínimos & 58 & 41,1 \\
\hline & De 4 a 5 salários mínimos & 40 & 28,4 \\
\hline & Mais de 7 salários mínimos & 29 & 20,6 \\
\hline \multirow{5}{*}{$\begin{array}{l}\text { Pessoas morando com } \\
\text { o indivíduo }\end{array}$} & Nenhuma ou uma pessoa & 32 & 22,6 \\
\hline & 2 pessoas & 20 & 14,2 \\
\hline & 3 pessoas & 40 & 28,4 \\
\hline & 4 pessoas & 35 & 24,8 \\
\hline & Mais de 4 pessoas & 14 & 10,0 \\
\hline \multirow[t]{5}{*}{ Cômodos na residência } & Até 2 cômodos & 14 & 9,9 \\
\hline & 3 cômodos & 23 & 16,3 \\
\hline & 4 cômodos & 45 & 31,9 \\
\hline & 5 cômodos & 34 & 24,1 \\
\hline & Mais de 5 cômodos & 25 & 17,8 \\
\hline \multirow{3}{*}{$\begin{array}{l}\text { Aglomeração } \\
\text { (npessosas/ncômodos) }\end{array}$} & $\leq 0,75$ & 50 & 35,4 \\
\hline & $0,76-1,00$ & 52 & 36,9 \\
\hline & $\geq 1,01$ & 39 & 27,6 \\
\hline
\end{tabular}


As tabelas 3 e 4 referem-se às características relacionadas ao trabalho e à microárea. Cabe destacar que os entrevistados assumiram a função de ACS há 40,9 meses em média, e a maioria fez algum curso de capacitação ainda durante o primeiro mês de trabalho $(84,7 \%)$. Cerca de um terço dos sujeitos relatou ter faltado no trabalho nos últimos trinta dias, os motivos referidos foram: doença $(41 \%)$, familiar doente $(30,8 \%)$, consulta médica $(17,9 \%)$ e outros $(10,3 \%)$.

Ao serem perguntados sobre a existência de aspecto relacionado ao esgotamento profissional, a maioria afirmou que havia $(84,4 \%)$, e foi a relação com a equipe (PSF e UBS) e com a comunidade que se sobressaíram, respectivamente, 37,8\% e 33,6\% (tabela 3). Quanto ao uso atual de medicação do tipo calmante, tranqüilizante ou antidepressivo, 24 entrevistados (17\%) afirmaram fazer uso regular, com o predomínio dos antidepressivos. Para identificar se o indivíduo trabalhava em uma microárea de risco, foi perguntado se o entrevistado acompanhava famílias que moram em favela, moradia coletiva (cortiço) ou área de invasão, 36,9\% responderam ter pessoas cadastradas que vivem nessas condições (tabela 3). 
Tabela 3 - Distribuição dos sujeitos quanto às características relacionadas ao trabalho, São Paulo ( $\mathrm{N}=141)$.

\begin{tabular}{|c|c|c|c|}
\hline Variável & Categoria & $\mathbf{N}$ & $\%$ \\
\hline \multirow[t]{2}{*}{$\begin{array}{l}\text { Tempo de trabalho } \\
\text { (meses) }\end{array}$} & $\leq 42$ meses & 72 & 51,0 \\
\hline & $>42$ meses & 69 & 48,9 \\
\hline Curso de capacitação & $\begin{array}{l}\text { Sim } \\
\text { Não }\end{array}$ & $\begin{array}{c}131 \\
10\end{array}$ & $\begin{array}{c}92,9 \\
7,1\end{array}$ \\
\hline \multirow[t]{2}{*}{$\begin{array}{l}\text { Tempo de início do } \\
\text { curso }\end{array}$} & 1 mês & 111 & 84,7 \\
\hline & 2 meses ou mais & 20 & 15,3 \\
\hline \multirow[t]{2}{*}{ Faltas no trabalho } & $\begin{array}{l}\text { Nenhuma falta } \\
\text { Uma falta }\end{array}$ & $\begin{array}{c}102 \\
22\end{array}$ & \multirow{2}{*}{$\begin{array}{l}72,3 \\
15,6 \\
12,1\end{array}$} \\
\hline & Duas ou mais faltas & 17 & \\
\hline \multirow{2}{*}{$\begin{array}{l}\text { Aspecto de } \\
\text { esgotamento } \\
\text { adicional }\end{array}$} & Não & 22 & 15,6 \\
\hline & Sim & 119 & 84,4 \\
\hline \multirow{5}{*}{$\begin{array}{l}\text { Qual aspecto de } \\
\text { esgotamento }\end{array}$} & Relação com equipe PSF+UBS & 45 & 37,8 \\
\hline & \multirow{2}{*}{$\begin{array}{l}\text { Relação com a comunidade } \\
\text { SIAB }\end{array}$} & 40 & 33,6 \\
\hline & & 15 & 29,4 \\
\hline & $\begin{array}{l}\text { Dificuldade nos serviços de } \\
\text { referência }\end{array}$ & 11 & 21,6 \\
\hline & Outros & 8 & 15,7 \\
\hline \multirow[t]{2}{*}{ Microárea de risco } & Não & 89 & 63,1 \\
\hline & Sim & 52 & 36,9 \\
\hline
\end{tabular}


A média de pessoas cadastradas por microárea foi de 517 . A população até 14 anos apresentou variação entre $9.9 \%$ e $41,6 \%$. A cobertura da população cadastrada por planos de saúde variou de zero a $57 \%$. O lixo era queimado ou depositado a céu aberto por $17,7 \%$ das famílias, e o destino do esgoto para fossas ou esgotos a céu aberto ocorreu em $36,9 \%$ das famílias (tabela 4).

Tabela 4 - Descrição das características das microáreas de acordo com dados do SIAB, São Paulo (N=141).

\begin{tabular}{lllc}
\hline \multicolumn{1}{c}{ Variável } & \multicolumn{1}{c}{ Categoria } & N & $\%$ \\
\hline Pessoas cadastradas* $^{*} \leq 530$ pessoas & 72 & 51,1 \\
& $>530$ pessoas & 69 & 48,9 \\
$\begin{array}{l}\text { Populaçãosde 14 } \\
\text { anos* }\end{array}$ & $\leq 20 \%$ & 67 & 47,5 \\
& $>20 \%$ & 74 & 52,5 \\
$\begin{array}{l}\text { Destino lixo por } \\
\text { famílias cadastradas }\end{array}$ & Coleta pública somente & 116 & 82,3 \\
& $\begin{array}{l}\text { Lixo queimado ou céu } \\
\text { aberto }\end{array}$ & 25 & 17,7 \\
$\begin{array}{l}\text { Destino esgoto por } \\
\text { famílias cadastradas }\end{array}$ & Esgoto público & 89 & 63,1 \\
& Fossa ou céu aberto & 52 & 36,9 \\
$\begin{array}{l}\text { Pessoas com plano de } \\
\text { saúde* }\end{array}$ & $\leq 20 \%$ & 67 & 47,5 \\
\hline
\end{tabular}

*A estratificação das variáveis foi realizada segundo a mediana.

\subsection{NÍVEIS DE ESGOTAMENTO PROFISSIONAL}

A segunda parte dos resultados refere-se à análise dos dados do Maslach Burnout Inventory (MBI). Foram observados níveis moderados ou altos de exaustão emocional em $70,9 \%$ dos entrevistados, de despersonalização em $34 \%$ e decepção em $47,5 \%$ (tabela 5 ). 
Tabela 5 - Distribuição dos sujeitos de acordo com as dimensões do esgotamento, São Paulo ( $\mathrm{N}=141)$.

\begin{tabular}{llll}
\hline \multicolumn{1}{c}{ Variável } & \multicolumn{1}{c}{ Categoria } & N & $\%$ \\
\hline \multirow{2}{*}{ Exaustão emocional } & Baixo & 41 & 29,1 \\
& Moderado & 36 & 25,5 \\
& Alto & 64 & 45,4 \\
Despersonalização & Baixo & 93 & \\
& Moderado & 34 & 66,0 \\
& Alto & 14 & 24,1 \\
& & & 9,9 \\
Decepção & Baixo & 74 & 52,5 \\
& Moderado & 35 & 24,8 \\
& Alto & 32 & 22,7 \\
\hline
\end{tabular}

As relações entre as três dimensões do esgotamento estão descritas nas tabelas 6, 7 e 8. Dos entrevistados com exaustão emocional alta (45\%), possuíam despersonalização alta $17,5 \%$ e decepção alta 32\%. Comparando com os indivíduos com exaustão baixa nota-se que as taxas de despersonalização alta e decepção alta são bem menores, respectivamente, $2,4 \%$ e $12,2 \%$ (tabelas 6 e 7 ). A maior parte dos entrevistados com despersonalização baixa também apresentava decepção baixa $(39 \%)$ (tabela 8$)$. 
Tabela 6. Distribuição dos sujeitos de acordo com as subescalas exaustão emocional e despersonalização e os níveis de gravidade, São Paulo (N=141).

\begin{tabular}{lllll}
\hline & \multicolumn{3}{c}{ Exaustão Emocional } \\
& & $\begin{array}{c}\text { Baixa } \\
\mathrm{N}(\%)\end{array}$ & $\begin{array}{c}\text { Moderada } \\
\mathrm{N}(\%)\end{array}$ & $\begin{array}{c}\text { Alta } \\
\mathrm{N}(\%)\end{array}$ \\
\hline \multirow{2}{*}{ Despersonalização } & Baixa & $34(82,9)$ & $27(75,0)$ & $32(50,8)$ \\
& Moderada & $6(14,6)$ & $7(14,9)$ & $20(31,7)$ \\
& Alta & $1(2,4)$ & $2(5,6)$ & $11(17,5)$ \\
\hline
\end{tabular}

Tabela 7. Distribuição dos sujeitos de acordo com as dimensões exaustão emocional e despersonalização e níveis de gravidade, São Paulo ( $N=141)$.

\begin{tabular}{llccc}
\hline & & \multicolumn{3}{c}{ Exaustão Emocional } \\
& & Baixa & Moderada & Alta \\
& $\mathrm{N}(\%)$ & $\mathrm{N}(\%)$ & $\mathrm{N}(\%)$ \\
\hline \multirow{2}{*}{ Decepção } & Baixa & $33(80,5)$ & $24(66,7)$ & $17(26,6)$ \\
& Moderada & $3(7,3)$ & $9(25)$ & $23(35,9)$ \\
& Alta & $5(12,2)$ & $3(8,3)$ & $24(37,5)$ \\
\hline
\end{tabular}

Tabela 8. Distribuição dos entrevistados de acordo com as subescalas despersonalização e decepção e os níveis de comprometimento, São Paulo $(\mathrm{N}=141)$.

\begin{tabular}{llccc}
\hline & \multicolumn{2}{c}{ Despersonalização } & \\
& & Baixa & Moderada & Alta \\
$\mathrm{N}(\%)$ & $\mathrm{N}(\%)$ & $2(1,4)$ \\
\hline Decepção & Baixa & $55(39,0)$ & $17(12,0)$ & $4(2,8)$ \\
& Moderada & $21(14,9)$ & $10(7,1)$ & $8(5,7)$ \\
& Alta & $17(12,0)$ & $7(4,9)$ & \\
\hline
\end{tabular}

Os critérios estabelecidos por Maslach, descritos no manual do $\mathrm{MBI}$, classificam apenas os indivíduos que apresentarem níveis iguais nas três 
subescalas, isto é, todas altas identifica esgotamento alto, todas moderadas, esgotamento moderado e, finalmente, todas baixas, esgotamento baixo. Segundo esses critérios, $34(24,1 \%)$ entrevistados tinham síndrome do esgotamento profissional, sendo 6 com nível alto, 1 moderado e 27 baixo. Entretanto, nota-se que seguindo esses critérios muitos sujeitos não puderam ser classificados, como por exemplo, aqueles com duas dimensões altas e uma baixa. Por esse motivo, optou-se também por classificar os entrevistados de acordo com o critério utilizado por Grunfeld e col., que considera que o indivíduo tem esgotamento profissional quando uma ou mais dimensões apresenta escore alto, independentemente do resultado das demais dimensões. Desta forma, 110 participantes (78\%) apresentaram esgotamento profissional.

\subsection{CARACTERÍSTICAS INDIVIDUAIS E DO TRABALHO ASSOCIADAS AO ESGOTAMENTO}

Para avaliar as condições associadas ao esgotamento foram utilizadas regressões logísticas univariadas das três subescalas do $\mathrm{MBI}$, assumindo as variáveis respostas como dicotômicas (moderada ou alta vs. baixa). Os valores dos odds ratios (razão de chances) e seus intervalos de $95 \%$ de confiança são apresentados nas tabelas a seguir. 


\subsubsection{Exaustão Emocional (0: Baixa - 1: Moderada e Alta)}

As tabelas 9, 10 e 11 descrevem as regressões logísticas univariadas para a dimensão exaustão emocional e as características sociodemográficas, da moradia e do trabalho dos entrevistados. Não foram observadas associações estatisticamente significativas entre as variáveis analisadas e os níveis de exaustão emocional moderado ou alto. 
Tabela 9. Odds ratio para exaustão emocional, segundo variáveis sociodemográficas, São Paulo ( $\mathrm{N}=141)$.

\begin{tabular}{|c|c|c|c|}
\hline Variável & OR & IC95\% & $\mathbf{p}$ \\
\hline \multicolumn{4}{|l|}{ Sexo (ref: masculino) } \\
\hline Feminino & 2,18 & 0,$63 ; 7,58$ & 0,22 \\
\hline \multicolumn{4}{|l|}{ Faixa etária (ref: $\leq 30$ anos) } \\
\hline 31 a 40 anos & 0,40 & 0,$14 ; 1,16$ & 0,09 \\
\hline 41 a 50 anos & 0,43 & 0,$14 ; 1,35$ & 0,15 \\
\hline Mais de 50 anos & 0,44 & 0,$13 ; 1,48$ & 0,18 \\
\hline \multicolumn{4}{|l|}{ Cor (ref: branca) } \\
\hline Parda & 1,05 & 0,$45 ; 2,48$ & 0,90 \\
\hline Negra & 0,71 & 0,$25 ; 2,01$ & 0,52 \\
\hline Outra & 0,67 & 0,$17 ; 2,59$ & 0,55 \\
\hline \multicolumn{4}{|c|}{ Estado civil (ref: casado/mora junto) } \\
\hline Solteiro & 1,21 & 0,$52 ; 2,81$ & 0,65 \\
\hline Viúvo/separado & 1,19 & 0,$41 ; 3,40$ & 0,75 \\
\hline \multicolumn{4}{|l|}{ Reliqião (ref: católico) } \\
\hline Evangélico & 0,80 & 0,$34 ; 1,89$ & 0,61 \\
\hline Outro & 0,98 & 0,$39 ; 2,48$ & 0,97 \\
\hline \multicolumn{4}{|c|}{ Escolaridade (ref: ensino fundamental/médio) } \\
\hline Outro (curso técnico) & 0,84 & 0,$31 ; 2,30$ & 0,73 \\
\hline Superior incompleto/completo & 3,61 & 0,$78 ; 16,62$ & 0,10 \\
\hline \multicolumn{4}{|c|}{ Renda familiar (ref: menos de 4 salários mínimos) } \\
\hline 4 a 5 salários mínimos & 0,54 & 0,$22 ; 1,31$ & 0,17 \\
\hline 6 a 7 salários mínimos & 1,06 & 0,$26 ; 4,37$ & 0,94 \\
\hline Mais de 7 salários mínimos & 0,47 & 0,$18 ; 1,25$ & 0,13 \\
\hline \multicolumn{4}{|c|}{ Pessoas morando com o indivíduo (ref: até 1 pessoa) } \\
\hline 2 pessoas & 1,36 & 0,$39 ; 4,80$ & 0,63 \\
\hline 3 pessoas & 1,20 & 0,$43 ; 3,32$ & 0,73 \\
\hline 4 pessoas & 0,87 & 0,$31 ; 2,42$ & 0,79 \\
\hline Mais de 4 pessoas & 1,67 & 0,$38 ; 7,32$ & 0,50 \\
\hline \multicolumn{4}{|c|}{$\begin{array}{l}\text { Cômodos na residência (ref: Até } 2 \\
\text { cômodos) }\end{array}$} \\
\hline 3 cômodos & 0,38 & 0,$07 ; 2,17$ & 0,28 \\
\hline 4 cômodos & 0,37 & 0,$07 ; 1,87$ & 0,23 \\
\hline 5 cômodos & 0,31 & 0,$06 ; 1,60$ & 0,16 \\
\hline Mais de 5 cômodos & 0,53 & 0,$09 ; 3,06$ & 0,47 \\
\hline \multicolumn{4}{|c|}{ Aglomeração (npessoas/cômodos) } \\
\hline \multicolumn{4}{|l|}{ Ref. $\leq 0,75$} \\
\hline $0,76-1,00$ & 1,16 & 0,$49 ; 2,75$ & 0,73 \\
\hline$\geq 1,01$ & 0,96 & 0,$39 ; 2,40$ & 0,94 \\
\hline
\end{tabular}

Tabela 10. Odds ratio para exaustão emocional, segundo a unidade básica de saúde, São Paulo ( $\mathrm{N}=141)$

\begin{tabular}{lccc}
\hline \multicolumn{1}{c}{ Variável } & OR & IC 95\% & p \\
\hline Unidade (ref: Boa Vista) & & & \\
Pq.Lapa & 0,79 & 0,$27 ; 2,27$ & 0,66 \\
Pêra & 1,58 & 0,$35 ; 7,18$ & 0,55 \\
São Jorge & 1,58 & 0,$52 ; 4,78$ & 0,42 \\
Vila Jaguara & 4,21 & 0,$80 ; 22,1$ & 0,09 \\
Vila Piauí & 1,23 & 0,$36 ; 4,18$ & 0,74 \\
\hline
\end{tabular}


Tabela 11. Odds ratio para exaustão emocional, segundo variáveis relacionadas ao trabalho dos sujeitos e à microárea, São Paulo (N=141).

\begin{tabular}{|c|c|c|c|}
\hline Variável & OR & IC 95\% & $p$ \\
\hline $\begin{array}{l}\text { Pessoas cadastradas (ref: } \leq \mathbf{5 3 0} \text { pessoas) } \\
>530 \text { pessoas }\end{array}$ & 1,53 & 0,$73 ; 3,19$ & 0,26 \\
\hline Microárea de risco (ref: Não) & & & \\
\hline $\begin{array}{l}\text { Sim } \\
\text { Tempo de inicio da capacitação (ref: } 1 \text { mês) }\end{array}$ & 1,90 & 0,$85 ; 4,21$ & 0,12 \\
\hline $\begin{array}{l}\text { Dois ou mais meses } \\
\text { Faltas no trabalho (ref: Nenhuma falta) }\end{array}$ & 0,86 & 0,$30 ; 2,46$ & 0,78 \\
\hline Uma falta & 0,76 & 0,$29 ; 2,01$ & 0,58 \\
\hline $\begin{array}{l}\text { Duas ou mais faltas } \\
\text { Aspecto de esgotamento adicional (ref: Não) }\end{array}$ & 3,27 & 0,$71 ; 15,2$ & 0,13 \\
\hline $\begin{array}{l}\text { População menor de } 14 \text { anos (ref: } \leq 20 \% \text { ) } \\
>20 \% \\
\text { Destino lixo coleta (ref: Coleta pública) }\end{array}$ & 0,81 & 0,$39 ; 1,69$ & 0,58 \\
\hline $\begin{array}{l}\text { Lixo queimado ou céu aberto } \\
\text { Destino esgoto (ref: Coleta pública) }\end{array}$ & 1,37 & 0,$50 ; 3,72$ & 0,54 \\
\hline Fossa ou céu aberto & 1,18 & 0,$55 ; 2,53$ & 0,67 \\
\hline $\begin{array}{l}\text { Pessoas com plano de saúde (ref: } \leq 20 \% \text { ) } \\
>20 \%\end{array}$ & 0,94 & 0,$45 ; 1,94$ & 0,86 \\
\hline
\end{tabular}

\subsubsection{Despersonalização (0: Baixa - 1: Moderada e Alta)}

Para essa dimensão do esgotamento, a análise univariada identificou que a partir dos 41 anos ocorreu uma diminuição progressiva do risco de ter despersonalização moderada ou alta. Os entrevistados que referiram ter cor negra tiveram maior chance de apresentar despersonalização, ter renda familiar entre 4 e 5 salários mínimos associou-se a menor chance, do mesmo modo que receber acima de sete salários mínimos. Com relação às condições de moradia, observou-se que os entrevistados que possuiam domicílios com 4 cômodos ou mais tiveram menor chance de ter despersonalização moderada ou alta, e aglomeração domiciliar igual ou maior que 0,76 associou-se a maior chance de despersonalização (tabela 12). 
Tabela 12 - Odds ratio para despersonalização, de acordo com as características sociodemográficas, São Paulo ( $\mathrm{N}=141)$.

\begin{tabular}{|c|c|c|c|}
\hline Variável & OR & IC 95\% & $\mathbf{p}$ \\
\hline \multicolumn{4}{|l|}{ Sexo (ref: masculino) } \\
\hline Feminino & 0,26 & 0,$07 ; 0,95$ & 0,04 \\
\hline \multicolumn{4}{|l|}{ Faixa etária (ref: $\leq 30$ anos) } \\
\hline 31 a 40 anos & 0,43 & 0,$18 ; 1,07$ & 0,07 \\
\hline 41 a 50 anos & 0,35 & 0,$13 ; 0,95$ & 0,04 \\
\hline Mais de 50 anos & 0,11 & 0,$03 ; 0,46$ & 0,00 \\
\hline \multicolumn{4}{|l|}{ Cor (ref: branca) } \\
\hline Parda & 1,52 & 0,$67 ; 3,45$ & 0,31 \\
\hline Negra & 2,86 & 1,$05 ; 7,79$ & 0,04 \\
\hline Outra & 0,58 & 0,$11 ; 3,00$ & 0,52 \\
\hline \multicolumn{4}{|c|}{ Estado civil (ref: casado/mora junto) } \\
\hline Solteiro & 1,21 & 0,$55 ; 2,64$ & 0,63 \\
\hline Viúvo/separado & 0,56 & 0,$18 ; 1,67$ & 0,29 \\
\hline \multicolumn{4}{|l|}{ Religião (ref: católico) } \\
\hline Evangélico & 1,66 & 0,$72 ; 3,80$ & 0,23 \\
\hline Outro & 1,46 & 0,$61 ; 3,51$ & 0,40 \\
\hline \multicolumn{4}{|c|}{ Escolaridade (ref: ensino fundamental/médio) } \\
\hline Outro (curso técnico) & 0,96 & 0,$35 ; 2,62$ & 0,94 \\
\hline Superior incompleto/completo & 0,51 & 0,$16 ; 1,66$ & 0,26 \\
\hline \multicolumn{4}{|c|}{ Renda familiar (ref: menos de 4 salários mínimos) } \\
\hline 4 a 5 salários mínimos & 0,33 & 0,$14 ; 0,82$ & 0,01 \\
\hline 6 a 7 salários mínimos & 0,64 & 0,$19 ; 2,14$ & 0,46 \\
\hline Mais de 7 salários mínimos & 0,37 & 0,$14 ; 0,99$ & 0,04 \\
\hline \multicolumn{4}{|c|}{$\begin{array}{l}\text { Pessoas morando com o indivíduo(ref: Até } 1 \\
\text { pessoa) }\end{array}$} \\
\hline 2 pessoas & 1,47 & 0,$46 ; 4,71$ & 0,52 \\
\hline 3 pessoas & 0,94 & 0,$34 ; 2,58$ & 0,91 \\
\hline 4 pessoas & 1,47 & 0,$54 ; 4,02$ & 0,46 \\
\hline Mais de 4 pessoas & 0,88 & 0,$22 ; 3,50$ & 0,85 \\
\hline \multicolumn{4}{|c|}{ Cômodos na residência (ref: Até 2 cômodos) } \\
\hline 3 cômodos & 0,51 & 0,$13 ; 2,00$ & 0,33 \\
\hline 4 cômodos & 0,23 & 0,$06 ; 0,80$ & 0,02 \\
\hline 5 cômodos & 0,23 & 0,$06 ; 0,87$ & 0,03 \\
\hline Mais de 5 cômodos & 0,14 & 0,$03 ; 0,60$ & 0,00 \\
\hline \multicolumn{4}{|c|}{$\begin{array}{l}\text { Aglomeração (npessoas/ncômodos) } \\
\text { ref } \leq 0,75\end{array}$} \\
\hline $0,76-1,00$ & 2,40 & 1,$01 ; 5,73$ & 0,04 \\
\hline$\geq 1,01$ & 2,47 & 0,$98 ; 6,22$ & 0,05 \\
\hline
\end{tabular}

No que se refere à UBS na qual o entrevistado trabalhava, não foi evidenciada diferença significativa entre os sujeitos para risco de despersonalização (tabela 13). 
Tabela 13 - Odds ratio para despersonalização, de acordo com as unidades básicas de saúde, São Paulo ( $\mathrm{N}=141)$.

\begin{tabular}{lccc}
\hline \multicolumn{1}{c}{ Variável } & OR & IC 95\% & p \\
\hline Unidade (ref: Boa Vista) & & & \\
Pq.Lapa & 1,29 & 0,$44 ; 3,80$ & 0,65 \\
Pêra & 2,22 & 0,$56 ; 8,82$ & 0,25 \\
São Jorge & 1,16 & 0,$40 ; 3,40$ & 0,78 \\
Vila Jaguara & 0,85 & 0,$23 ; 3,13$ & 0,81 \\
Vila Piauí & 0,95 & 0,$28 ; 3,29$ & 0,94 \\
\hline
\end{tabular}

Os participantes que referiram ter faltado no trabalho uma vez nos últimos trinta dias apresentaram maior chance de despersonalização moderada ou alta, assim como quando o destino dado ao lixo foi queimado ou desprezado a céu aberto. Por outro lado, o fato da microárea ter apresentado $20 \%$ ou mais das pessoas cadastradas com plano de saúde associou-se a menor chance de despersonalização (tabela 14). 
Tabela 14. Odds ratio para despersonalização, segundo as características do trabalho e da microárea, São Paulo ( $N=141)$.

$\frac{\text { Variável }}{\text { Pessoas cadastradas (ref: } \leq 530 \text { pessoas) }}$

$>530$ pessoas

$1,01 \quad 0,46 ; 2,21 \quad 0,98$

Microárea de risco (ref: Não)

Sim

$1,56 \quad 0,76 ; 3,18 \quad 0,22$

Tempo de inicio da capacitação (ref: 1 mês)

Dois ou mais meses

$0,76 \quad 0,27 ; 2,13 \quad 0,60$

Faltas no trabalho (ref: Nenhuma falta)

Uma falta

$3,02 \quad 1,18 ; 7,76 \quad 0,02$

Duas ou mais faltas

$1,76 \quad 0,62 ; 5,07 \quad 0,29$

Aspecto de esgotamento adicional (ref: Não)

Sim

$1,45 \quad 0,53 ; 4,00 \quad 0,47$

População menor de 14 anos (ref: $\leq 20 \%$ )

$>20 \%$

$1,63 \quad 0,80 ; 3,30 \quad 0,18$

Destino lixo coleta (ref: Coleta pública)

Lixo queimado ou céu aberto

$3,07 \quad 1,27 ; 7,44 \quad 0,01$

Destino esgoto (ref: Esgoto público)

Fossa ou céu aberto

$1,78 \quad 0,87 ; 3,63 \quad 0,11$

Pessoas com plano de saúde (ref: $\leq \mathbf{2 0 \%}$

$>20 \%$

$0,45 \quad 0,22 ; 0,92 \quad 0,03$ 


\subsubsection{Decepção (0: Baixa - 1: Moderada e Alta)}

Ao observar a tabela 15 , nota-se uma tendência de queda do risco para decepção moderada ou alta quanto maior a faixa etária. A aglomeração domiciliar, de maneira semelhante ao verificado na despersonalização, mostrou-se associada a maior chance de decepção moderada ou alta.

Tabela 15. Odds ratio para decepção, de acordo com as características sociodemográficas, São Paulo ( $\mathrm{N}=141)$.

\begin{tabular}{|c|c|c|c|}
\hline Variável & OR & IC $95 \%$ & $\mathbf{p}$ \\
\hline \multicolumn{4}{|l|}{ Sexo (ref: masculino) } \\
\hline Feminino & 2,59 & 0,17 & 0,$66 ; 10,18$ \\
\hline \multicolumn{4}{|l|}{ Faixa etária (ref: $\leq 30$ anos) } \\
\hline 31 a 40 anos & 0,80 & 0,62 & 0,$33 ; 1,96$ \\
\hline 41 a 50 anos & 0,37 & 0,04 & 0,$14 ; 0,97$ \\
\hline Mais de 50 anos & 0,15 & 0,00 & 0,$04 ; 0,49$ \\
\hline \multicolumn{4}{|l|}{ Cor (ref: branca) } \\
\hline Parda & 1,48 & 0,32 & 0,$69 ; 3,17$ \\
\hline Negra & 1,55 & 0,38 & 0,$59 ; 4,08$ \\
\hline Outra & 1,70 & 0,42 & 0,$46 ; 6,22$ \\
\hline \multicolumn{4}{|c|}{ Estado civil (ref: casado/mora junto) } \\
\hline Solteiro & 0,91 & 0,80 & 0,$43 ; 1,94$ \\
\hline Viúvo/separado & 0,88 & 0,78 & 0,$34 ; 2,27$ \\
\hline \multicolumn{4}{|l|}{ Religião (ref: católico) } \\
\hline Evangélico & 2,17 & 0,06 & 0,$96 ; 4,89$ \\
\hline Outro & 0,90 & 0,81 & 0,$39 ; 2,11$ \\
\hline \multicolumn{4}{|c|}{ Escolaridade (ref: ensino fundamental/médio) } \\
\hline Outro (curso técnico) & 0,68 & 0,43 & 0,$26 ; 1,80$ \\
\hline Superior incompleto/completo & 0,82 & 0,69 & 0,$30 ; 2,23$ \\
\hline \multicolumn{4}{|c|}{ Renda familiar (ref: menos de 4 salários mínimos) } \\
\hline 4 a 5 salários mínimos & 0,52 & 0,12 & 0,$23 ; 1,19$ \\
\hline 6 a 7 salários mínimos & 0,65 & 0,47 & 0,$20 ; 2,12$ \\
\hline Mais de 7 salários mínimos & 0,93 & 0,87 & 0,$38 ; 2,38$ \\
\hline \multicolumn{4}{|c|}{ Pessoas morando com o indivíduo (ref: Até 1 pessoa) } \\
\hline 2 pessoas & 0,55 & 0,32 & 0,$17 ; 1,80$ \\
\hline 3 pessoas & 1,42 & 0,46 & 0,$56 ; 3,62$ \\
\hline 4 pessoas & 1,71 & 0,27 & 0,$65 ; 4,51$ \\
\hline Mais de 4 pessoas & 0,96 & 0,95 & 0,$27 ; 3,43$ \\
\hline \multicolumn{4}{|c|}{ Cômodos na residência (ref: Até 2 cômodos) } \\
\hline 3 cômodos & 0,36 & 0,14 & 0,$09 ; 1,42$ \\
\hline 4 cômodos & 0,58 & 0,39 & 0,$17 ; 2,01$ \\
\hline 5 cômodos & 0,39 & 0,15 & 0,$11 ; 1,41$ \\
\hline Mais de 5 cômodos & 0,51 & 0,33 & 0,$13 ; 1,97$ \\
\hline \multicolumn{4}{|c|}{$\begin{array}{l}\text { Aglomeração (npessoas/ncômodos) ref } \\
\leq 0,75\end{array}$} \\
\hline $0,76-1,00$ & 2,24 & 0,04 & 1,$01 ; 4,97$ \\
\hline$\geq 1,01$ & 1,87 & 0,15 & 0,$80 ; 4,39$ \\
\hline
\end{tabular}


Na tabela 16 verifica-se que os ACS da UBS Vila Jaguará apresentaram menor chance de ter decepção moderada ou alta que os da UBS Boa Vista. Tabela 16. Odds ratio para decepção, segundo unidade básica de saúde dos entrevistados, São Paulo ( $N=141)$.

\begin{tabular}{lccc}
\hline \multicolumn{1}{c}{ Variável } & OR & IC 95\% & p \\
\hline Unidade (ref: Boa Vista) & & & \\
Pq.Lapa & 0,35 & 0,$12 ; 1,02$ & 0,054 \\
Pêra & 0,24 & 0,$05 ; 1,06$ & 0,06 \\
São Jorge & 1,55 & 0,$54 ; 4,44$ & 0,41 \\
Vila Jaguara & 0,27 & 0,$08 ; 0,97$ & 0,04 \\
Vila Piauí & 0,71 & 0,$22 ; 2,22$ & 0,55 \\
\hline
\end{tabular}

A avaliação das questões relacionadas ao trabalho e às características da microárea evidenciou que ter faltado 2 ou mais vezes no trabalho nos últimos trinta dias, acompanhar microárea de risco e ter acima de $20 \%$ população cadastrada constituída por indivíduos até 14 anos aumentaram a chance de decepção moderada ou alta (tabela 17).

Tabela 17. Odds ratio para decepção, de acordo com as características do trabalho e da microárea, São Paulo (N=141).

\begin{tabular}{|c|c|c|c|}
\hline Variável & OR & IC95\% & $\mathbf{p}$ \\
\hline $\begin{array}{l}\text { Tempo de trabalho (em meses) (ref: } \leq 42 \text { meses) } \\
>42 \text { meses }\end{array}$ & 1,02 & 0,$53 ; 1,98$ & 0,94 \\
\hline $\begin{array}{l}\text { Pessoas cadastradas (ref: } \leq \mathbf{5 3 0} \text { pessoas) } \\
>530 \text { pessoas } \\
\text { Microárea de risco (ref: Não) }\end{array}$ & 0,91 & 0,$47 ; 1,77$ & 0,79 \\
\hline $\begin{array}{l}\text { Sim } \\
\text { Tempo de inicio da capacitação (ref: } 1 \text { mês) }\end{array}$ & 2,47 & 1,$22 ; 4,98$ & 0,01 \\
\hline $\begin{array}{l}\text { Dois ou mais meses } \\
\text { Faltas no trabalho (ref: Nenhuma falta) }\end{array}$ & 0,83 & 0,$32 ; 2,17$ & 0,71 \\
\hline Uma falta & 1,06 & 0,$42 ; 2,66$ & 0,90 \\
\hline $\begin{array}{l}\text { Duas ou mais faltas } \\
\text { Aspecto de esgotamento adicional (ref: Não) }\end{array}$ & 3,04 & 1,$00 ; 9,26$ & 0,05 \\
\hline $\begin{array}{l}\text { Sim } \\
\text { População menor de } 14 \text { anos (ref: } \leq 20 \% \text { ) }\end{array}$ & 1,72 & 0,$67 ; 4,41$ & 0,26 \\
\hline $\begin{array}{l}>20 \% \\
\text { Destino lixo coleta (ref: Coleta pública) }\end{array}$ & 2,81 & 1,$41 ; 5,57$ & 0,00 \\
\hline $\begin{array}{l}\text { Lixo queimado ou céu aberto } \\
\text { Destino esgoto (ref: Esgoto público) }\end{array}$ & 1,51 & 0,$63 ; 3,61$ & 0,35 \\
\hline Fossa ou céu aberto & 1,17 & 0,$59 ; 2,32$ & 0,65 \\
\hline $\begin{array}{l}\text { Pessoas com plano de saúde (ref: } \leq \mathbf{2 0} \% \text { ) } \\
>20 \%\end{array}$ & 0,78 & 0,$40 ; 1,52$ & 0,46 \\
\hline
\end{tabular}


A partir das respostas obtidas no $\mathrm{MBI}$, foram construídos três modelos de regressão logística multivariável, que estão descritos na tabela 18. No primeiro modelo verifica-se que decepção (moderada/alta) é variável que preditora independente para a exaustão emocional (moderada ou alta), os indivíduos que apresentaram decepção moderada/alta tiveram risco de exaustão 3 vezes maior (IC95\% 1,19;7,92; $p=0,02$ ). No segundo modelo observa-se que as variáveis faixa etária mais de 50 anos, exaustão emocional moderada/alta, destino do lixo queimado ou céu aberto apresentaram associação estatisticamente significativa para o desfecho despersonalização moderada/alta. Pertencer a faixa etária mais de 50 anos foi identificado como fator de proteção (ORajustado 0,12; IC95\% $0,03 ; 0,50 ; p<0,001)$. Os sujeitos com exaustão moderada ou alta tiveram maior risco (ORajustado 3,18; IC95\%1,22;8,30; $p=0,01$ ). Assim como, os ACS que possuíam famílias cadastradas que referiam depositar lixo a céu aberto ou queimávam-no, apresentaram maior chance para despersonalização (ORajustado 3,09;IC95\% 1,19;8,06; $p=0,02$ ). Nesse modelo houve ajuste pela variável faixa etária (variável de confusão). O terceiro modelo avaliou a dimensão decepção e evidenciou que houve associação significativa com exaustão emocional moderada/alta (ORajustado 3,92; IC95\% 1,40;11,0; $p<0,001$ ). Para esse modelo a faixa etária e a população até 14 anos foram variáveis de ajuste (variáveis de confusão). 
Tabela 18. Odds ratio brutos $\mathrm{e}$ ajustados para as dimensões do esgotamento, segundo as variáveis que permaneceram nos modelos da regressão logística multivariável, São Paulo ( $N=141)$.

\begin{tabular}{|c|c|c|c|c|}
\hline Variável & OR $_{\text {bruto }}$ & OR $_{\text {ajustado }}$ & IC 95\% & $p$ \\
\hline \multicolumn{5}{|l|}{ Exaustão emocional } \\
\hline \multicolumn{5}{|l|}{ Decepção (ref: Baixa) } \\
\hline Moderada e alta & 5,94 & 3,06 & 1,$19 ; 7,92$ & 0,02 \\
\hline \multicolumn{5}{|l|}{ Despersonalização } \\
\hline \multicolumn{5}{|c|}{ Faixa etária (ref: $\leq 30$ anos) ${ }^{1}$} \\
\hline 31 a 40 anos & 0,43 & 0,51 & 0,$20 ; 1,33$ & 0,17 \\
\hline 41 a 50 anos & 0,35 & 0,47 & 0,$16 ; 1,35$ & 0,16 \\
\hline Mais de 50 anos & 0,11 & 0,16 & 0,$04 ; 0,67$ & 0,01 \\
\hline \multicolumn{5}{|c|}{ Exaustão emocional (ref:Baixa) } \\
\hline Moderada e alta & 3,38 & 3,32 & 1,$26 ; 8,74$ & 0,01 \\
\hline \multicolumn{5}{|c|}{ Destino lixo (ref: Coleta pública) } \\
\hline $\begin{array}{l}\text { Lixo queimado ou céu } \\
\text { aberto }\end{array}$ & 3,07 & 3,23 & 1,$21 ; 8,62$ & 0,02 \\
\hline \multicolumn{5}{|l|}{ Aglomeração (ref: $\leq 0,75)$} \\
\hline $0,76-1,00$ & 2,40 & 2,07 & 0,$79 ; 5,45$ & 0,14 \\
\hline$\geq 1,01$ & 2,47 & 1,95 & 0,$69 ; 5,54$ & 0,28 \\
\hline \multicolumn{5}{|l|}{ Decepção } \\
\hline \multicolumn{5}{|c|}{ Exaustão emocional (ref Baixa) } \\
\hline $\begin{array}{c}\text { Moderada e alta } \\
\text { Faixa etária (ref: } \leq \mathbf{3 0})^{2}\end{array}$ & 5,94 & 3,92 & 1,$40 ; 11,0$ & $<0,001$ \\
\hline 31 a 40 anos & 0,80 & 1,21 & 0,$41 ; 3,56$ & 0,73 \\
\hline 41 a 50 anos & 0,37 & 0,69 & 0,$21 ; 2,21$ & 0,53 \\
\hline Mais de 50 anos & 0,15 & 0,25 & 0,$06 ; 1,06$ & 0,06 \\
\hline \multicolumn{5}{|c|}{ População até 14 anos (ref: $\leq 20 \%)^{2}$} \\
\hline$>20 \%$ & 2,81 & 2,25 & 0,$91 ; 5,59$ & 0,08 \\
\hline
\end{tabular}

1 modelo ajustado por faixa etária

2 modelo ajustado por faixa etária e a população menor de 14 anos categorizadas 


\subsection{PREVALÊNCIA DE TMC E CARACTERÍSTICAS}

\section{ASSOCIADAS}

Os participantes foram classificados em caso suspeitos de TMC de acordo com pontuação no SRQ-20 (escore igual ou maior a 8), o que ocorreu para 43,3\% (IC95\% 35,0 a 51,5). Cabe mencionar que cinco entrevistados solicitaram acompanhamento pela equipe de saúde mental.

Para avaliar as associações entre as variáveis foram realizadas regressões logísticas univariadas considerando a variável dependente SRQ-20 como dicotômica (caso e não caso). Avaliando as características sociodemográficas, nota-se que os entrevistados da faixa etária de 41 a 50 anos apresentaram uma chance menor de ter TMC, quando comparados àqueles com 30 anos ou menos, assim como ter referido renda familiar acima de 7 salários mínimos diminuiu a chance de TMC. O número de pessoas que moram com o indivíduo e a quantidade de cômodo na residência não foram identificados como fatores preditores de TMC (tabela 19). 
Tabela 19 - Odds ratio para TMC, de acordo com as variáveis sociodemográficas, São Paulo ( $\mathrm{N}=141)$.

\begin{tabular}{|c|c|c|c|}
\hline Variável & OR & IC 95\% & $\mathbf{p}$ \\
\hline \multicolumn{4}{|l|}{ Sexo (ref: masculino) } \\
\hline Feminino & 8,57 & 1,$07 ; 68,9$ & 0,04 \\
\hline \multicolumn{4}{|l|}{ Faixa etária (ref: $\leq 30$ anos) } \\
\hline 31 a 40 anos & 0,61 & 0,$25 ; 1,46$ & 0,26 \\
\hline 41 a 50 anos & 0,36 & 0,$13 ; 0,96$ & 0,04 \\
\hline Mais de 50 anos & 0,42 & 0,$15 ; 1,21$ & 0,11 \\
\hline \multicolumn{4}{|l|}{ Cor (ref: branca) } \\
\hline Parda & 0,67 & 0,$31 ; 1,45$ & 0,30 \\
\hline Negra & 1,25 & 0,$48 ; 3,29$ & 0,65 \\
\hline Outra & 0,66 & 0,$17 ; 2,49$ & 0,53 \\
\hline \multicolumn{4}{|c|}{ Estado civil (ref: casado/mora junto) } \\
\hline Solteiro & 0,92 & 0,$43 ; 1,97$ & 0,82 \\
\hline Viúvo/separado & 1,08 & 0,$42 ; 2,79$ & 0,87 \\
\hline \multicolumn{4}{|l|}{ Religião (ref: católico) } \\
\hline Evangélico & 1,98 & 0,$89 ; 4,45$ & 0,09 \\
\hline Outro & 2,13 & 0,$91 ; 4,97$ & 0,08 \\
\hline \multicolumn{4}{|c|}{ Escolaridade (ref: ensino fundamental/médio) } \\
\hline Outro (curso técnico) & 0,47 & 0,$17 ; 1,33$ & 0,15 \\
\hline Superior incompleto/completo & 0,55 & 0,$19 ; 1,58$ & 0,27 \\
\hline \multicolumn{4}{|c|}{ Renda familiar (ref: menos de 4 salários mínimos) } \\
\hline 4 a 5 salários mínimos & 0,58 & 0,$26 ; 1,31$ & 0,19 \\
\hline 6 a 7 salários mínimos & 0,48 & 0,$14 ; 1,62$ & 0,24 \\
\hline Mais de 7 salários mínimos & 0,39 & 0,$15 ; 1,00$ & 0,05 \\
\hline \multicolumn{4}{|c|}{$\begin{array}{l}\text { Pessoas morando com o indivíduo (ref: Até } 1 \\
\text { pessoa) }\end{array}$} \\
\hline 2 pessoas & 0,48 & 0,$15 ; 1,50$ & 0,20 \\
\hline 3 pessoas & 0,59 & 0,$23 ; 1,50$ & 0,27 \\
\hline 4 pessoas & 0,93 & 0,$36 ; 2,44$ & 0,89 \\
\hline Mais de 4 pessoas & 0,24 & 0,$06 ; 1,03$ & 0,055 \\
\hline \multicolumn{4}{|c|}{ Cômodos na residência (ref: Até 2 cômodos) } \\
\hline 3 cômodos & 0,58 & 0,$15 ; 2,21$ & 0,42 \\
\hline 4 cômodos & 0,78 & 0,$23 ; 2,63$ & 0,69 \\
\hline 5 cômodos & 0,41 & 0,$11 ; 1,46$ & 0,17 \\
\hline Mais de 5 cômodos & 0,35 & 0,$09 ; 1,36$ & 0,13 \\
\hline \multicolumn{4}{|l|}{ Aglomeração (ref: $\leq 0,75)$} \\
\hline $0,76-1,00$ & 1,19 & 0,$54 ; 2,61$ & 0,66 \\
\hline$\geq 1,01$ & 1,29 & 0,$55 ; 3,00$ & 0,56 \\
\hline
\end{tabular}

A tabela 20 mostra que os indivíduos que trabalhavam na UBS São Jorge apresentaram maior chance de ter TMC do que aqueles da UBS Boa Vista, sem diferenças significativas entre as outras unidades. 
Tabela 20 - Odds ratio para TMC, de acordo com as unidades básicas desaúde, São Paulo (N=141).

\begin{tabular}{lccc}
\hline \multicolumn{1}{c}{ Variável } & OR & IC 95\% & p \\
\hline Unidade (ref: Boa Vista) & & & \\
Pq.Lapa & 1,29 & 0,$44 ; 3,80$ & 0,65 \\
Pêra & 0,74 & 0,$16 ; 3,40$ & 0,70 \\
São Jorge & 3,25 & 1,$13 ; 9,34$ & 0,03 \\
Vila Jaguara & 2,78 & 0,$82 ; 9,39$ & 0,10 \\
Vila Piauí & 1,82 & 0,$56 ; 5,92$ & 0,32 \\
\hline
\end{tabular}

Observando as características relacionadas ao trabalho e à microárea verificamos que os ACS que acompanhavam uma microárea de risco mostraram chance maior de apresentar TMC, do mesmo modo que ter faltado duas ou mais vezes no trabalho no último mês também associou-se a maior risco de ser considerado caso pelo SRQ-20 (tabela 21).

Os dados fornecidos pelo SIAB (número de pessoas cadastradas, população até 14 anos, destino do lixo e esgoto) e os demais aspectos ligados ao trabalho como tempo de trabalho, tempo de início da capacitação e aspecto de esgotamento adicional, não foram identificados como variáveis preditoras para risco de TMC (tabela 21). 
Tabela 21 - Odds ratio para TMC, segundo as características do trabalho e da microárea, São Paulo ( $\mathrm{N}=141)$.

\begin{tabular}{|c|c|c|c|}
\hline Variável & OR & IC 95\% & $p$ \\
\hline $\begin{array}{l}\text { Tempo de trabalho (ref. } \leq 42 \text { meses) } \\
>42 \text { meses }\end{array}$ & 1,14 & 0,$59 ; 2,22$ & 0,69 \\
\hline $\begin{array}{l}\text { Pessoas cadastradas (ref: } \leq \mathbf{5 3 0} \text { pessoas) } \\
>530 \text { pessoas }\end{array}$ & 0,81 & 0,$41 ; 1,57$ & 0,53 \\
\hline Microárea de risco (ref: Não) & & & \\
\hline $\begin{array}{l}\text { Sim } \\
\text { Tempo de inicio da capacitação (ref: } 1 \text { mês) }\end{array}$ & 2,90 & 1,$43 ; 5,89$ & 0,003 \\
\hline $\begin{array}{l}\text { Dois ou mais meses } \\
\text { Faltas no trabalho (ref: Nenhuma falta) }\end{array}$ & 0,93 & 0,$36 ; 2,42$ & 0,88 \\
\hline Uma falta & 1,68 & 0,$67 ; 4,26$ & 0,27 \\
\hline $\begin{array}{l}\text { Duas ou mais faltas } \\
\text { Aspecto de esgotamento adicional (ref: } \\
\text { Não) }\end{array}$ & 4,04 & 1,$32 ; 12,36$ & 0,01 \\
\hline Sim & 1,78 & 0,$68 ; 4,68$ & 0,24 \\
\hline $\begin{array}{l}\text { População menor de } 14 \text { anos (ref: } \leq \mathbf{2 0} \%) \\
>20 \% \\
\text { Destino lixo coleta (ref: Coleta pública) }\end{array}$ & 1,42 & 0,$72 ; 2,77$ & 0,31 \\
\hline $\begin{array}{l}\text { Lixo queimado ou céu aberto } \\
\text { Destino esgoto (ref: Esgoto público) }\end{array}$ & 1,26 & 0,$53 ; 3,00$ & 0,59 \\
\hline Fossa ou céu aberto & 1,75 & 0,$87 ; 3,49$ & 0,11 \\
\hline $\begin{array}{l}\text { Pessoas com plano de saúde (ref: } \leq \mathbf{2 0} \% \text { ) } \\
>20 \%\end{array}$ & 0,89 & 0,$46 ; 1,73$ & 0,73 \\
\hline
\end{tabular}




\subsection{TMC E ESGOTAMENTO PROFISSIONAL}

Indivíduos classificados como casos de TMC, obtiveram escores altos para as dimensões do esgotamento profissional: exaustão emocional em 78,7\%, despersonalização em 19,7\% e decepção em 42,6\%. As associações das subescalas do $\mathrm{MBI}$ com o SRQ-20 estão descritas na tabela 22. Observase que as três subescalas são fortemente associadas com TMC.

Tabela 22 - Odds ratio para transtorno mental comum, de acordo com as dimensões do esgotamento. São Paulo ( $N=141)$

\begin{tabular}{|c|c|c|c|}
\hline Variável & OR & IC 95\% & $\mathbf{p}$ \\
\hline \multicolumn{4}{|c|}{ Exaustão emocional (ref: Baixa) } \\
\hline Moderada e alta & 12,26 & 4,$06 ; 37,02$ & $<0,001$ \\
\hline \multicolumn{4}{|c|}{ Despersonalização (ref: Baixa) } \\
\hline Moderada e alta & 2,55 & 1,$25 ; 5,20$ & 0,01 \\
\hline \multicolumn{4}{|l|}{ Decepção (ref: Baixa) } \\
\hline Moderada e alta & 7,41 & 3,$49 ; 15,74$ & $<0,001$ \\
\hline
\end{tabular}

O modelo final de regressão logística para TMC identificou que as variáveis preditoras independentes da probabilidade dos entrevistados apresentarem de TMC foram duas dimensões do esgotamento: exaustão emocional (moderada/alta) e decepção (moderada/alta). A microárea de risco é variável de ajuste (tabela 23). 
Tabela 23 - Odds ratios brutos e ajustados para transtorno mental comum, de acordo com as variáveis que permaneceram no modelo final de regressão multivariável. São Paulo ( $N=141)$

\section{Variável}

$$
\text { OR }_{\text {bruto }}
$$

$$
\text { OR }_{\text {ajustado }}
$$

IC 95\% p

Exaustão emocional (ref: Baixa)

Moderada e alta 12,26

7,75

2,$43 ; 24,71$

$<0,001$

Decepção (ref: Baixa)

Moderada e alta

7,41

4,63

2,$05 ; 10,50$

$<0,001$

Microárea de risco (ref:

Não) *

Sim

2,90

2,20

0,$95 ; 5,09$

0,06

*variável de confusão

Cabe destacar que os modelos finais de regressão logística para as variáveis de desfecho foram testados para interação, esta não foi constatada. 


\section{DISCUSSÃO}

\subsection{SUMÁRIO DOS RESULTADOS}

O presente estudo evidenciou altas proporções de ACS com níveis moderados ou altos de exaustão emocional e decepção. Também foi verificada elevada frequência de prováveis casos de TMC entre os ACS investigados. A análise estatística das variáveis de exposição e de desfecho evidenciou, fundamentalmente, que as dimensões de esgotamento profissional estão associadas entre si e com TMC.

\subsection{LIMITAÇÕES METODOLÓGICAS}

Foram investigados apenas 141 ACS de uma única região do município de São Paulo, contratados pela mesma organização, o que limita a capacidade de generalização dos resultados e o poder estatístico do estudo, além de aumentar o risco de resultados falsos-negativos (FLETCHER e col.,1996).

É possível que alguns ACS que apresentavam síndrome do esgotamento profissional e/ou TMC não tenham participado do estudo, por estarem afastados ou terem mudado de profissão, o que pode ter levado a uma subestimativa da frequência de esgotamento profissional e de TMC. Também é necessário considerar o viés de aferição associado ao estudo de casos de longa duração, que se refere àqueles indivíduos que têm 
condições crônicas recorrentes, mas controláveis, que poderiam estar bem no momento da entrevista e não serem diagnosticados (FLETCHER e col., 1996). Assim, por exemplo, os ACS com transtornos ansiosos ou depressivos, podem não terem sido considerados casos suspeitos de TMC. Desta forma, a associação entre esgotamento profissional e transtorno mental comum também pode ter sido subestimada.

Outro ponto a ser considerado é que o SRQ-20, elaborado pela WHO (1994) para rastrear possíveis casos de transtorno mental em serviços de atenção primária e na comunidade, não fornece diagnósticos formais, somente evidencia casos suspeitos de TMC.

O grande predomínio de mulheres $(92,2 \%)$ neste estudo impossibilitou fazer inferências para o sexo masculino.

Aspectos importantes que não foram avaliados no presente estudo são os eventos de vida produtores de estresse (violência, conflito familiar, separação, doença ou morte de parente etc) que poderiam estar relacionados ao esgotamento profissional e a TMC nos ACS.

Com relação à microárea, não foi possível saber a proporção de famílias cadastradas que viviam em favela, cortiço ou área de invasão (microárea de risco), o que acabou colocando em um mesmo grupo, os ACS com muitas famílias cadastradas vivendo nessas condições e os ACS com 
poucas famílias assim, o que leva a uma diluição de associações quando elas de fato existem.

Outra dificuldade encontrada foi a obtenção de dados sobre os ACS do município de São Paulo, o que impossibilitou a comparação das características dos indivíduos que participaram deste estudo com dados do município. A busca pela informação também foi realizada na Associação Municipal dos ACS, no sindicato da categoria (Sindcomunitário) e na Secretaria Municipal de Saúde.

Finalmente, o desenho transversal do presente estudo não permite estabelecer relação temporal entre esgotamento e TMC.

\subsection{ESGOTAMENTO PROFISSIONAL}

Nessa pesquisa, a síndrome do esgotamento profissional foi constatada em $24,1 \%$ dos entrevistados, estando acima da encontrada por TAMAYO (1997) nos trabalhadores de enfermagem $(16,1 \%)$, abaixo da prevalência descrita por HERNÁNDEZ (2003) no estudo com médicos e enfermeiros (30,3\%), e é compatível com a relatada por GUNDERSEN (2001) para profissionais de saúde (25 a 30\%).

Considerando o critério de GRUNFELD e col. (2000) que define a existência de esgotamento quando pelo menos uma das dimensões 
apresentar escore alto, a taxa de esgotamento nos entrevistados foi de $78 \%$. Esse número é maior do que o encontrado por GLASBERG e col. (2007), que utilizou o mesmo critério para avaliar esgotamento em oncologistas brasileiros e encontrou prevalência de 68,6\%.

Quando as dimensões do esgotamento são observadas separadamente, verifica-se que exaustão emocional alta e decepção alta foram mais freqüentemente identificadas do que a despersonalização, respectivamente, 45\%, 32\% e 9,93\%. Esse achado é semelhante ao encontrado por ALBALADEJO e col. (2004) ao pesquisar trabalhadores de enfermagem de um hospital em Madrid, que observou que taxa de despersonalização foi a menor entre as subescalas $(8,4 \%)$. Entretanto, MARTÍN e col. (2001) descreveram que a despersonalização alta foi a dimensão do esgotamento mais identificada $(31,2 \%)$, seguida pela exaustão emocional alta $(30,6 \%)$ e pela decepção alta $(24,2 \%)$ em médicos, enfermeiros e auxiliares de enfermagem da atenção primária. CARVALHO (1995) mostrou taxas bem menores de exaustão alta $(17,7 \%)$ e decepção alta (22\%), e maior despersonalização alta $(19,7 \%)$ em professores da rede estadual de ensino do $1^{\circ}$ e $2^{\circ}$ graus em São Paulo, quando comparados aos ACS entrevistados.

É importante ressaltar que os ACS apresentaram uma das maiores taxas de exaustão emocional e decepção ao comparar com vários profissionais pesquisados na literatura mundial. Entretanto, a taxa de 
despersonalização não acompanhou as outras duas dimensões. Levantamos algumas possibilidades que podriam justificar os resultados observados:

a) o fato do ACS pertencer à comunidade na qual trabalha, conviver com as famílias cadastradas há muito tempo, mesmo antes de se tornar ACS, pode ter gerado um vínculo afetivo que dificulte o desenvolvimento da despersonalização, apesar da exaustão ser tão elevada;

b) a representação que pode existir para o ACS da sua valorização pela comunidade, uma vez que passa a pertencer a uma equipe de saúde, adquire saberes diferenciados com repercussão no acesso aos serviços. O domínio de certos conteúdos e práticas referentes à biomedicina, diferenciado em relação ao conhecimento popular, confere prestígio social ao ACS (NUNES e col., 2002);

c) o fato de fazer parte do PSF, que tem como um dos eixos a humanização, pode ter gerado conflito quando os entrevistados se depararam com algumas questões do MBI ligadas à despersonalização, por exemplo, "percebo que trato algumas pessoas da microárea como se fossem objetos impessoais". BENEVIDES-PEREIRA (2002) corrobora com a idéia de que algumas questões do $\mathrm{MBI}$ podem causar um certo impacto no entrevistado, uma vez que entram em desacordo com a postura esperada de um bom profissional; 
d) a investigação pode ter sido realizada no momento em que a exaustão estava predominando e evolução para despersonalização ainda estaria por vir.

\subsubsection{Exaustão Emocional}

Um dos achados nessa pesquisa que merece grande destaque é que mais da metade dos entrevistados apresentou escores moderado ou alto de exaustão $(70,9 \%)$, tendo em vista que essa dimensão é considerada a fase inicial do esgotamento, conseqüência da sobrecarga de trabalho e dos conflitos interpessoais, e está ligada à sensação de estar além dos limites, sem recursos físicos e emocionais, e ao desenvolvimento da despersonalização como mecanismo de defesa, de auto-proteção (MASLACH, 2005).

Essa alta prevalência de exaustão moderada ou alta nos ACS pode ter algumas explicações:

a) a dinâmica laboral diferenciada, uma vez que esses indivíduos residem na área em que trabalham, tornando fácil o acesso dos clientes/vizinhos com demandas de saúde, física e emocional, à casa do ACS, fora do horário de trabalho. CORDES e DOUGUERTY (1993) descreveram que dentre as variáveis relacionadas a altos níveis de esgotamento a relação 
entre o ocupante do cargo e a sua clientela se destaca, principalmente quando o cliente tem dor, angústia ou raiva (CHERNISS,1992), realidade que faz parte do cotidiano dos trabalhadores do PSF;

b) o enfrentamento situações complexas (famílias em condições socioeconômicas precárias, dinâmicas familiares de difícil intervenção, violência, tráfico de drogas), muitas vezes sem uma rede social instituída, sem a equipe interdisciplinar necessária para discussão e elaboração das ações, o que pode gerar sobrecarga de trabalho, insatisfação, sensação de inadequação e incompetência;

c) o conflito e a ambigüidade de papel: a profissão de ACS foi regulamentada recentemente, em 2002 (MS, 2002), e alguns autores descrevem que a identidade do ACS ainda está em construção (SILVA e DALMASO, 2001). Para NUNES e col. (2002), o fato do ACS vivenciar a realidade do bairro onde mora e trabalha, e ser capacitado a partir de referênciais biomédicos, faz do ACS portador de muitas as contradições.

O estudo de MASLACH e JACKSON (1981) evidenciou que a exaustão é maior em solteiros e divorciados, em pessoas com maior grau de escolaridade, o que não foi verificado nos ACS investigados. GRUNFELD (2000) e CARLOTTO e PALAZZO (2006) também não evidenciaram associações significativas entre variáveis demográficas e as dimensões do esgotamento. Esses resultados reforçam o postulado de que o 
esgotamento ocorre, em grande parte, devido às características do trabalho e não do indivíduo (MASLACH, 2005), embora não seja possível afastar a possibilidade de erro tipo II, pelo pequeno tamanho da presente amostra.

O risco para exaustão foi maior nos ACS com decepção moderada/alta (OR ajustado:3,19, IC95\% 1,19;7,92; $p=0,02)$, o que se está de acordo com o achado descrito por McMANUS e col. (2002) ao investigar médicos ingleses constataram que a decepção aumenta a exaustão emocional. O fato dessas dimensões terem os mesmos desencadeantes (sobrecarga de trabalho, conflitos, falta de recursos institucionais e interpessoais), pode justificar esse resultado.

A avaliação dos dados dos ACS não evidenciou associação entre o número de indivíduos acompanhados (cadastradas na microárea) e as dimensões do esgotamento. Da mesma maneira, GLASBERG e col (2007) identificaram que o número de pacientes acompanhados pelos oncologistas não teve associação significativa com as dimensões do esgotamento. Entretanto, MARTÍNEZ (1997) evidenciou que os profissionais da atenção primária e secundária que cuidavam de mais pacientes apresentaram diferença significativa para maior exaustão emocional. CARLOTTO e PALAZZO (2006) também encontraram que quanto maior o número de alunos acompanhados, maior a exaustão. 


\subsubsection{Despersonalização}

Nessa pesquisa, 34\% dos participantes apresentam nível moderado ou alto de despersonalização. Geralmente essa dimensão se desenvolve como resposta à exaustão emocional e está articulada à ansiedade, irritabilidade e falta de motivação. O indivíduo passa a tratar os clientes e colegas como objetos e merecedores dos problemas que possuem (MASLACH e JACKSON, 1981; MASLACH, 2005).

Nos ACS entrevistados, o fato de pertencer à faixa etária maior que 50 anos protegeu contra despersonalização moderada/alta, o que está de acordo com TIRONI (2005), que defende que quanto maior a idade (acima de 40 anos) menor o risco para despersonalização, e com MASLACH e JACKSON (1981), que relatam que essa dimensão predomina em jovens. As últimas autoras também descrevem que a despersonalização é menor quanto maior o grau de escolaridade. O presente estudo não mostrou associação com relação à escolaridade.

MASLACH e JACKSON (1981) descreveram a despersonalização como uma estratégia defensiva de confrontamento desenvolvida pelo trabalhador para lidar com a exaustão emocional, assim essas duas dimensões estão relacionadas. No presente estudo também encontramos forte associação entre exaustão emocional e despersonalização. 
Cabe destacar que os ACS que tinham famílias cadastradas que referiram depositar lixo a céu aberto ou queimá-lo, também evidenciaram maior risco para despersonalização moderada/alta. É possível que essas famílias possuíam condições socioeconômicas precárias, podendo adoeçer mais, demandar mais atenção, cuidados, e estariam expostas a mais conflitos e violência, podendo apresentar mais TMC (PATEL e KLEINMAN, 2003). Para lidar com essas situações e com a própria exaustão o ACS desenvolveria a despersonalização como mecanismo de defesa e de preservação.

\subsubsection{Decepção (reduzida realização pessoal)}

Quase metade dos ACS entrevistados (47,5\%) apresentou nível de decepção moderado ou alto. Essa dimensão do esgotamento está ligada à queda da produtividade, falta de realização no trabalho, sensação de incompetência, e pode ser exacerbada por falta de apoio social e de oportunidades de desenvolvimento profissional (MASLACH, 2005).

O maior risco para decepção nos sujeitos com exaustão emocional moderada/alta corrobora com a idéia de que a exaustão emocional seria a fase inicial do esgotamento, podendo surgir a decepção posteriormente. Essas duas dimensões do esgotamento estão ligadas aos mesmos fatores predisponentes individuais e do trabalho (MASLACH e JACKSON, 1981, LEITER,1993). 
MARTÍNEZ (1997) identificou que os profissionais da atenção primária e secundária que cuidavam de mais pacientes apresentaram maior risco para decepção, o que difere do observado nos ACS, já que não se obteve maiores níveis de decepção naqueles com maior número de pessoas cadastradas na microárea.

\subsubsection{Aspecto adicional relacionado ao esgotamento}

A maioria dos participantes (84.4\%) referiu haver aspecto adicional relacionado ao esgotamento, destacando a relação com a equipe (PSF e UBS), que foi o aspecto mais frequentemente relatado $(37,6 \%)$. Esse achado está de acordo com SHINN e col. (1984) que asseveram que os conflitos interpessoais com colegas de trabalho são uma das principais causas de esgotamento e estressores maiores que a relação com os clientes. PICK e LEITER (1991) reafirmam essa idéia ao evidenciarem que a maioria das enfermeiras investigadas considerou que seu esgotamento seria o resultado de conflito entre colegas.

Para NUNES e col. (2002) os conflitos podem estar relacionados às divergentes expectativas sobre o trabalho do ACS, uma vez que a equipe de saúde espera um trabalho mais técnico e a comunidade apresenta demandas mais pessoais. 
Inicialmente, tínhamos a idéia de que a comunidade pudesse ser o fator estressor mais importante no cotidiano do ACS, pelas demandas variadas socioeconômicas, condições de saúde, situações de violência, rede social desarticulada, além da procura do ACS fora do horário de funcionamento da UBS, muitas vezes à noite, no final de semana e em vários locais da comunidade (feira, salão de beleza, igreja). Nesse sentido, a relação com a comunidade foi descrita pelos entrevistados como o segundo aspecto mais relacionado ao esgotamento.

\subsection{TRANSTORNO MENTAL COMUM}

A prevalência de suspeitos de TMC nos ACS investigados foi $43,3 \%$ (IC95\% 35,0 a 51,5). Esse número está acima do encontrado por alguns pesquisadores brasileiros em estudos populacionais: LIMA e col. (1999), 22,7\% na população de Pelotas; ALMEIDA F e col. (1997), 31\% em São Paulo; LUDERMIR e MELO FILHO (2002), 35\% em Olinda. A taxa encontrada nos ACS se assemelha a descrita por MARI e col. (1987), que ao avaliar 875 indivíduos atendidos em serviços de atenção primária em São Paulo, evidenciaram morbidade psiquiátrica em $47 \%$ em um Centro de Saúde da Brasilândia, 50\% no Hospital do Servidor Público Estadual e 56\% no Centro de Saúde da Barra Funda, o que leva à constatação de que os ACS possuem prevalência de TMC mais semelhante a da população doente que faz seguimento nos serviços de saúde do que a da população em geral. 
Com relação ao sexo, vários estudos corroboram a maior prevalência de TMC no sexo feminino (COUTINHO e col., 1999; LUDERMIR e MELO FILHO, 2002, LIMA e col., 1999). Tal comparação não pôde ser realizada já que apenas $7,2 \%$ dos entrevistados era do sexo masculino, e apenas 1 homem apresentou SRQ-20 positivo.

Outro aspecto relevante é constatado na variável renda familiar, à medida que ela aumenta o OR diminui, e o valor de $\mathbf{p}$ decresce, até alcançar 0,05 na categoria "mais de 7 salários mínimos", apesar da variável não ter permanecido no modelo múltiplo, fazendo suscitar a hipótese de que quanto maior a renda familiar menor seria a chance do indivíduo ter TMC, o que é mencionado por LUDERMIR e MELO FILHO (2002) ao descreverem a renda como uma das variáveis relativas às condições de vida associada a TMC.

Esses mesmos autores descreveram outras variáveis socioeconômicas e ligadas à estrutura ocupacional associadas a TMC, como escolaridade, posse de bens duráveis, condições de moradia, ocupação, exclusão do mercado formal de trabalho. O que difere do encontrado nos ACS, pois não houve associação significativa de TMC com as variáveis socioeconômicas e relacionadas ao trabalho. 
GOLDBERG e HUXLEY (1992) explicam que os TMC constituem causa importante de dias perdidos de trabalho, além de elevarem a demanda nos serviços de saúde, desse modo, geram alto custo social e econômico.

\subsection{ESGOTAMENTO PROFISSIONAL E TRANSTORNO MENTAL COMUM}

MASLACH (2005) salienta que nos últimos anos surgiu a discussão do significado da associação do esgotamento com depressão e suscitam a hipótese do esgotamento não ser precursor da depressão, mas uma forma de doença mental. Entretanto, para AHOLA e col. (2006) é possível que o esgotamento profissional seja uma fase no desenvolvimento da depressão, nas situações em que o fator que precede o início da depressão está relacionado ao trabalho.

ALUJA (1997) defende que depressão, ansiedade e transtornos somatoformes são as principais respostas psicológicas à síndrome do esgotamento. GRAHAM e col. (2002) consideram o esgotamento um fator preditor de transtorno mental. Para WRIGHT e CROPANZANO (1998) a exaustão emocional pode comprometer a saúde mental dos trabalhadores. McMANUS e col. (2002) concordam com esses autores ao demonstrar associação significativa de morbidade psiquiátrica com exaustão emocional e decepção, em médicos do Reino Unido. Essas afirmações são compatíveis com os resultados encontrados nos ACS investigados, que 
evidenciaram que as variáveis preditoras independentes da probabilidade de TMC foram duas dimensões do esgotamento: a exaustão emocional moderada ou alta e a decepção moderada ou alta.

A questão sobre o uso atual de medicação do tipo calmante, tranqüilizante ou antidepressivo, foi elaborada pela suspeita da provável relação entre o consumo dessas medicações e prevalência de TMC e/ou esgotamento. Afirmaram fazer uso regular 24 entrevistados (17\%), com o predomínio dos antidepressivos. Essa taxa foi maior que a encontrada por LIMA e col. (2006) no estudo transversal realizado na população urbana de Pelotas ( $n=3542$ ), que evidenciou prevalência de consumo de psicofármacos de $9,9 \%$, sendo os benzodiazepínicos a classe consumida por mais da metade daqueles que faziam uso dessas medicações. O estudo de MARI e col. (1993) na população de São Paulo, a prevalência do uso de psicotrópicos foi de $11,7 \%$ nos homens e $24,6 \%$ nas mulheres, também com predomino de benzodiazepínicos e evidenciando que o consumo aumenta com a idade e se houver morbidade psiquiátrica. McCRAINE e col. (1987) relata que uma das conseqüências do esgotamento é o uso de drogas tranqüilizantes. Não encontramos associação entre uso dessas medicações, esgotamento profissional e/ou transtorno mental comum. 


\subsection{IMPLICAÇÕES PARA ORGANIZAÇÃO DE SERVIÇOS E PARA PESQUISA}

O PSF inclui parcelas crescentes da população brasileira na proposta de assistência humanizada, integral, contínua, com resolutividade e qualidade, adequada às necessidades de saúde da população adscrita, destacando a perspectiva da família no ambiente em que vive. Para tornar possível sua implantação e execução dos objetivos do programa, lança-se mão de um considerável contingente de profissionais de saúde, principalmente ACS. Esses trabalhadores enfrentam situações complexas (p.ex. dinâmicas familiares de difícil intervenção, violência, tráfico de drogas), muitas vezes sem uma rede social instituída e sem a equipe interdisciplinar necessária. Alguns autores descrevem a problemática e condições de trabalho em que as ESF estão imersas, destacando a sobrecarga do atendimento, o que gera dificuldades em efetuar o planejamento e discutir a dinâmica do trabalho, composição básica insuficientes das equipes, insuficiência de profissionais com perfil proposto pelo programa, várias modalidades de contratos de trabalho, heterogeneidade na estrutura física das unidades, expectativas contraditórias e conflitos das ESF com os poderes locais, conflitos nas relações com a população, quando as equipes não conseguem atender a demanda, entre outras questões (COSTA e col., 2000, SOUZA, 2000). 
É diante desse cenário que se torna imprescindível refletir sobre o trabalho dos ACS, sendo imperativa a necessidade de novas pesquisas, com amostras maiores e mais representativas, envolvendo também os demais profissionais das ESF. Estudos com delineamentos longitudinais, desde o momento em que os profissionais ingressam na profissão, investigação da sobrecarga de trabalho, de eventos de vida produtores de estresse, avaliação dos motivos de afastamento, rotatividade, devem contribuir para uma melhor compreensão dos fatores causais, implicando na elaboração de estratégias organizacionais e individuais de intervenção, como treinamento, capacitação e supervisão dos ACS e demais profissionais das ESF, de modo a minimizar os danos à saúde dos mesmos e melhorar a qualidade de vida no trabalho, repercutindo fundamentalmente na qualidade dos serviços prestados a população. 


\section{REFERÊNCIAS BIBLIOGRÁFICAS}

Ahola K, Honkonen T, Kivimäki M, Virtanen M, Isometsä E, Aromaa A, Lönnqvist J. Contribution of burnout to the association between job strain and depression: the health 2000 study. J Occup Environ Med. 2006;48:1023-30.

Albaladejo R, Villanueva R, Ortega P, Astasio P, Calle ME, Dominguez V. Síndrome de burnout en el personal de enfermería de un hospital de Madrid. Rev Esp Salud Publica. 2004;78:505-16.

Almeida Filho N, Mari JJ, Coutinho ESF, França JF, Fernandes J, Andreoli SB, Busnello ED. Brazilian multicentric study of psychiatric morbidity. $\mathrm{Br} \mathrm{J}$ Psychiatry. 1997;171:524-9.

Aluja A. Burnout profesional en maestro y su relación con indicadores de salud mental. Bol Psicol. 1997;55: 47-61.

Armstrong, BK; White, E; Saracci, R. Principles of Exposure Measurement in Epidemiology. Oxford University Press Inc, New York, 1992

Brasil. Lei $n^{\circ}$ 10.507.de 10 de julho de 2002. Cria a profissão de agente comunitário de saúde e dá outras providências. Brasília, DF;2002.

Benevides-Pereira, AMT. Burnout: o processo de adoecer pelo trabalho. In: Benevides-Pereira AMT, organizador. Burnout: quando o trabalho ameaça o bem-estar do trabalhador. São Paulo: Casa do Psicólogo:21-91;2002. 
Carlotto MS e Palazzo LS. Síndrome de burnout e fatores associados: um estudo epidemiológico com professores. Cad Saude Publica. 2006; 22(5):1017-26.

Carvalho MMB. O professor- um professional sua saúde e a educação em saúde na escola. [tese de doutorado] Faculdade de Saúde Pública. São Paulo 1995.

Cherniss C. Long-term consequences of burnout: an exploratory study. $J$ Organ Behav.1992;13:1-11.

Cordes C, Dougherty T W. A review and integration of research on job burnout. Acad Manage Rev.1993;18(4):632-636.

Costa MBS, Lima CB, Oliveira CP. Atuação do enfermeiro no Programa de Saúde da Família (PSF) no Estado da Paraíba. Rev Bras Enferm. 2000;53:149-52.

Coutinho ESF, Almeida $\mathrm{F}^{\circ} \mathrm{N}$, Mari JJ, Rodrigues L. Minor Psychiatris morbidity and internal migration in Brazil. Soc Psychiatry Psychiatr Epidemiol. 1996;31:173-9.

Delgado A C. Revisión teórica del burnout o desgaste profesional en trabajadores de la docencia. Caesura. 1993;2:47-65.

Fletcher HR, Fletcher SW, Wagner HE. Epidemiologia Clínica: elementos essenciais. Porto Alegre: Artes Médicas;1996.

Folkman S, Lazarus RS, Dunkel-Schetter C, DeLongis A, Gruen RJ. Dynamics of stressful encounter: cognitive appraisal, coping and encounter outcomes. J Pers Soc Psychol. 1986;59:992-1003. 
Fortes PAC, Spinetti S R. O Agente Comunitário de Saúde e a privacidade de informações dos usuários. Cad Saude Publica. 2004; 20(5):1328-1333.

Freudenberger HJ. Staff burn-out. J Soc Issues. 1974;30(1):159-165.

Freudenberger HJ. The staff burn-out syndrome in alternatives institutions. Prof Psychol Res Pr. 1975; 12(1): 73-82.

Glasberg J, Horiuti L, Novais M A B, Canavezzi A Z, Miranda V C, Chicoli F $A$, et al. Prevalence of the burnout syndrome among brazilian medical oncologists. Rev Assoc Med Bras. 2007;53:85-9.

Goldberg D, Huxley P. Commom mental disorders: a bio-social model. London: Tavistock, 1992.

Graham J, Ramirez AJ, Cull A, Finlay I, Hoy A, Richards MA. Job stress and satisfaction among palliative physicians. Palliat Med. 1996;10:185-94.

Grunfeld E, Whelan T J, Zitzelsberger L, Willan A R, Montesanto B, Evans W K. Câncer care workers in Ontário: prevalence of burnout, job stress and job satisfaction. CMAJ. .2000;163(2):166-9.

Gundersen L. Physician burnout. Ann Intern Med. 2001;135:145-8.

Harding, T.W.; Arango, M.V.; Baltazar, J.;Climent, C.E.; Ibrahim, H.H.A.;Ignácio, L.L.; Murhy, R.S.; Wig, N.N. Mental disorders in primary health care:estudy of their frequency and diagnosis in four developing countries. Psychol Med. 1980;10:231-41.

Hernández JR. Estrés y burnout en profesionales de la salud de los niveles primario e secundario de atención. Rev. Cubana Salud Publica. 2003;29: 103-10. 
Katz MH. Multivariable Analysis: A primer for readers of medical research. Ann Intern Med. 2003;138:644-650.

Leiter M P. Burnout and engagement in the workplace: a contextual analysis. Adv Motiv Achiev.1993;11:275-302.

Levy FM, Matos PES, Tomita NE. Programa de Agentes Comunitários de Saúde: percepção de usuários e trabalhadores da saúde. Cad Saude Public. 2004;20(1):197-203.

Lima MS, Beria JU, Tomasi E, Conceição AT, Mari JJ. Stressful life events and minor psychiatric disorders: na estimate of the population attibutabl fraction in brazilian commmunity-based study. Int J Psychiatry Med. 1996; $26: 213-24$.

Ludermir AB, Melo Filho DA. Condições de vida e estrutura ocupacional associadas a transtornos mentais comuns. Rev Saude Publica. 2002;36(2),213-21.

Mari JJ, Willians P. A validity study of a psychiatric screening questionnaire (srq-20) in primary care in the city of São Paulo. $\mathrm{Br} J$ Psychiatry. 1986;148:23-26.

Mari JJ, Almeida Filho N, Coutinho E, Andreoli SB, Miranda CT, Streiner D. The epidemiology of psychotropic use in the city of São Paulo. Psychol Med. 1993;23(2):467-74.

Martín MAC, Fernández FB, Goméz RN, Martínez FC. Prevalencia y factores asociados al burnout en un area de salud. Aten Primaria. 2001;27(5):313-7. 
Martínez JCA. Aspectos Epidemiológicos del syndrome de burnout en personal sanitario. Rev Esp Salud Publica. 1997;71(3)293-303.

Maslach C, Jackson S E. The measurement of experienced burnout. J Occup Behav. 1981;2:99-113.

Maslach C, Jackson S E, Leiter MP. Maslach Burnout Inventory Manual. Mountain View:CPP;1996.

Maslach C, Leiter MP. The truth about burnout: how organization cause personal stress and what to do about it. San Francisco: Jossey-Bass, 1997.

Maslach C, Goldberg J. Prevention of burnout: news perspectives. Appl Prev Psychol. 1998;7:63-74.

Maslach C. Entendendo o burnout- In: Rossi AM, Perrewé PL, Sauter SL, organizadores. Stress e Qualidade de Vida no trabalho. 1. ed. São Paulo: Atlas;2005. p. 41-55.

McCraine EW, Lambert VA, Lambert JCR. Work stress, hardiness and burnoutamong hospital staff nurses. Nurs Res. 1987;36(6):374-8.

McManus IC, Winder BC, Gordon D. The causal links between stress and burnout in longitudinal study of UK doctors. Lancet. 2002;359: 2089-90.

Mendes R. Patologia do Trabalho. São Paulo: Atheneu; 2003. Introdução ao estudo dos mecanismos patogênicos do trabalho; p 115-20.

MS - Ministério da Saúde. Fundação Nacional de Saúde. Saúde dentro de casa. Programa de Saúde da Família. Brasília, DF; 1994. 
MS - Ministério da Saúde. Manual Saúde da Família: uma estratégia para reorientação do modelo assistencial. Brasília, DF;1998.

MS - Ministério da Saúde. Secretaria de Políticas Públicas. Programa Saúde da Família. Rev. Saúde Pública. 2000; 34(3): 316-9.

MS - Ministério da Saúde. Informe da Atenção Básica. Regulamentação do vínculo de Agentes Comunitários de Saúde. Brasília N 15, ano 3, fev 2002. Disponível em: http:// dtr2004.saude.gov.br/dab/informe_ab.php

MS - Ministério da Saúde. Programa Saúde da Família. Projeto de Expansão e consolidação do programa saúde da família - PROESF [acesso dezembro 2006]. Disponível em: http:// dtr2004.saude.gov.br/dab/documentos/informes/psfinfo17.pdf

MS - Ministério da Saúde. Política Nacional de Atenção Básica. [acesso 26 de março 2006] Disponível em: http://dtr2004.saude.gov.br/dad/documentos/pactos/documentos/ pactos_vol4.pdf

MS - Ministério da Saúde. Atenção Básica e Saúde da Família. Consolidado histórico da cobertura da saúde da família. [acesso 20 março 2007]. Disponível em: http://dtr2004.saude.gov.br/dab/abnumeros.php

Nunes MO, Trad BL, Almeida BA, Homem CR, Melo MCIC. O Agente Comunitário de Saúde: construção da identidade desse personagem híbrido e polifônico. Cad Saude Publica. 2002;18: 1639-1646.

OPAS - Organização Pan-americana de Saúde. Indicadores de saúde no Brasil: conceito e aplicações. 2002 [acesso 20 agosto 2007]. Disponível em: www.opas.org.br/sistemas/arquivos/matriz.pdf 
Patel V, Kleinman.A. Poverty and common mental disorders in developing countries. Bull World Health Organ. 2003;8198):609-15.

Pedrosa JIS, Teles JBM. Consensos e diferenças em equipes do Programa Saúde da Família. Rev Saude Publica. 2001;35:303-11.

Pick D, Leiter MP. Nurses' perceptions of the nature and causes of burnout: a comparison of self-reportings and standardized measures. Can J Nurs Res. 1991;23:33-48.

Prefeitura de São Paulo. Secretaria Municipal de Planejamento. Mapas e Dados. [acesso 4 setembro 2007]. Disponível em: http://sempla.prefeitura.sp.gov.br/mapasedados.php

Prosser D, Johnson S, Kuipers E, Dunn G, Szmukler G, Reid P, Bebbington $P$, Thorncroft $G$. Mental health, burnout and job satisfaction in longitudinal study of mental health staff. Soc Psychiatry Psychiatr Epidemiol.1999;34:295-300.

Rijk AE, Le Blanc PM, Schaufeli WB, DeJonge J. Active coping and need for control as moderators of job demand-control model: effects on burnout. $J$ Occup Organ Psychol.1998;71(1):1-19.

Schaufeli WB, Buunk BP. Handbook of work and health psychology. London: Wiley, 1996.

Schaufeli WB, Enzmann D. The Burnout companion to study: a critical analysis. London: Taylor \& Francis, 1998.

Secretaria Municipal de Saúde. Gestão plena no SUS. Revista Saúde São Paulo.São Paulo;2004. 
Shinn M, Rosário M, Morch H, Chestnut DE. Coping with job stresse and burnout in humam services. Journal of personality and social psychology. 1984;46:864-76.

Silva JA, Dalmaso A S. Agentes comunitários de saúde: choque de povo. São Paulo: Hucitec, 2001. O Agente Comunitário de Saúde; p.75-113.

Silva JA, Dalmaso A S. Agente Comunitário de Saúde, o ser, o saber o fazer. Cad Saude Publica. 2004;20(5): 1433-1437.

Souza HM. Programa de saúde da família. Rev Bras Enferm. 2000;53:7-16.

Souza MF. A Cor-Agem do PSF. São Paulo: Hucitec; 2001. A cor do PSF (princípios orientadores); p.35-40.

Spickard AJ, Gabbe SG, Christensen JF. Mid-career burnout in generalist and specialist physicians. JAMA. 2002;288(12):1447-50.

Tamayo, M R Relação entre a síndrome do burnout e os valores organizacionais no pessoal de enfermagem de dois hospitais públicos. [dissertação de mestrado]. Brasília: Universidade de Brasília; 1997.

Tamayo MR, Tróccoli BT. Exaustão emocional: relação com a percepção de suporte organizacional e com as estratégia de coping no trabalho. Estudos de Psicologia. 2002; 7:37-46.

Tironi, M. O. S. A Síndrome de burnout em médicos pediatras: um estudo em duas organizações hospitalares. [dissertação de mestrado na internet]. Salvador: Universidade Federal da Bahia; 2005 [acesso em 07 fev 2007]. Disponível em: http://pospsi.ufba.br/pdf/marcia tironi.pdf

World Health Organization. The ICD-10 classification of mental and behavioural disorders. Geneva; 1992. 
World Health Organization. Division of mental Helth. $A$ user's guide to the self reporting questionnaire. Geneva; 1994.

Wright TA, Cropanzano R. Emocional exaustion as a predictor of job performance and voluntary turnover. J Appl Psychol. 1998;83:486-93. 


\section{ANEXOS}

\section{Anexo 1}

\section{QUESTIONÁRIO COM OS DADOS: SOCIODEMOGRÁFICOS,} RELACINADOS AO TRABALHO E À SAÚDE DOS SUJEITOS

1. Nome:

Data de nascimento:

2. estado civil: 1casada( ) 2solteiro( ) 3viúvo( ) 4separada( ) 5mora junto( )

3. sexo: 1( )m 2( )f

4. Cor(auto-referida): 1( )branca 2( )parda 3( )negra 4( )amarela 5 ( )outra

5. Com relação a escolaridade, qual o curso mais elevado que você freqüentou?

1( )ensino fundamental ou $1^{\circ} \mathrm{grau} \quad 2$ ( )ensino médio ou $2^{\circ} \mathrm{grau}$

3( )pre'-vestibular 4( )superior incompleto $\quad 5$ ( ) superior completo 6( )outro:

6. Qual a sua religião? 1( )católica 2( ) evangélica

3( )testemunha de Jeová 4( ) espírita
5( )protestante 6( )outra

7. Há quanto tempo você mora na área em que trabalha?

8. Quantas pessoas moram com você?

9. Qual é a renda familiar mensal?

10. Quantos cômodos têm na sua residência? 
11. Há quanto tempo trabalha como agente comunitário de saúde?

12. Quantos indivíduos estão cadastrados na sua microárea?

13. Na sua microárea existe cortiços, favela, ou área de invasão? ( ) $\operatorname{sim} \quad$ ( )não

14. Você realizou algum curso de capacitação? ( )sim （ )não 15. Se sim, quanto tempo após o início das suas atividades como agente comunitário de saúde?

16. Você precisou faltar no trabalho no último mês? ( )sim ( )não 17.Se sim, Quantas vezes? e qual o motivo?

18. Você está fazendo uso de algum tipo de calmante, tranqüilizante ou antidepressivo? ( )sim ( )não

19. Se sim, qual?

Quebra: passar para SRQ-20 e MBI

20. Na sua opinião, existe outro aspecto do trabalho, que pode estar relacionado com o esgotamento que não perguntei ainda? ( )sim ( )não 21. Se sim, qual? 1( ) relação com a comunidade 2( )relação com equipe 3( )relação com os outros ACS 4( )outro 


\section{Anexo 2}

SELF REPORTING QUESTIONNAIRE-20

O Sr.(Sra.) poderia por favor responder às seguintes perguntas a respeito da sua saúde nos últimos trinta dias.

1. Tem dores de cabeça freqüentes?

SIM NÃO

2. Tem falta de apetite?

SIM NÃO

3. Dorme mal?

SIM NÃO

4. Assusta-se com facilidade?

SIM NÃO

5. Tem tremores na mão?

SIM NÃO

6. Sente-se nervoso(a), tenso(a), ou preocupado(a)?

SIM

NÃO

7. Tem má digestão?

SIM NÃO

8. Tem dificuldade de pensar com clareza?

SIM

NÃO

9. Tem se sentido triste ultimamente?

SIM

NÃO

10. Tem chorado mais do que de costume?

SIM

NÃO

11.Encontra dificuldades para realizar com satisfação suas atividades diárias?

12.Tem dificuldade para tomar decisões?

13. Tem dificuldades no serviço? (seu trabalho é penoso, Ihe causa sofrimento)

14. É incapaz de desempenhar um papel útil em sua vida?

15. Tem perdido o interesse pelas coisas?

SIM

NÃO

16. Você se sente uma pessoa inútil, sem préstimo?

SIM

NÃO

17. Tem tido a idéia de acabar com a vida?

SIM

NÃO

18. Sente-se cansado (a) o tempo todo?

SIM

NÃO

19. Tem sensações desagradáveis no estômago?

SIM

NÃO

20. Você se cansa com facilidade?

SIM

NÃO

SIM

NÃO 
Anexo 3

MASLACH BURNOUT INVENTORY

\begin{tabular}{|l|l|l|l|l|l|l|}
\hline 0 & 1 & 2 & 3 & 4 & 5 & 6 \\
\hline Nunca & Algumas vezes & No máximo & Algumas & Uma vez & Poucas & Diariamente \\
& por ano no & uma vez por & vezes ao & por & vezes por & \\
& máximo & mês & mês & semana & semana & \\
& & & & & & \\
\hline
\end{tabular}

Freqüência (0 a 6)

1. Sinto-me emocionalmente sugado pelo meu trabalho.

2. Sinto-me esausto(a) ao final do dia.

3. Sinto-me muito cansado(a) quando acordo de manhã e tenho que enfrentar outro dia de trabalho.

4. C__ Consigo facilmente entender como as pessoas da microárea se sentem sobre as coisas.

5. ___ Percebo que trato as pessoas da microárea como se fossem objetos impessoais.

6. Trabalhar com pessoas o dia todo é um grande esforço para mim.

7. Consigo lidar de forma eficiente com os problemas das pessoas da microárea.

8. Sinto-me completamente esgotado(a) pelo meu trabalho.

9. ___ Sinto que influencio de forma positiva as vidas das pessoasatravés de meu trabalho.

10. Tornei-me mais indiferente com relação às pessoas desde que assumi este trabalho. 
11.___ Sinto que este trabalho está me deixando muito menos emocional.

12. Sinto-me cheio(a) de energia.

13. Sinto-me frustado(a) com meu emprego.

14.___ Sinto que estou trabalhando muito duro neste trabalho.

15. N__ Na verdade, não me importo com o que acontece a algumas pessoas da microárea.

16.___ Trabalhar diretamente com pessoas coloca muita pressão sobre mim.

17.___ Consigo criar um ambiente relaxado com as pessoas da microárea.

18._Sinto-me entusiasmado(a) após trabalhar diretamente com as pessoas da microárea.

19.___ Consegui fazer várias coisas importantes neste trabalho.

20. ___ Sinto que não tenho mais um pingo de criatividade ou imaginação.

21. Em meu trabalho, lido com os problemas emocionais de forma muita calma.

22. Sinto que as pessoas da microárea às vezes me culpam por seus problemas. 


\section{Anexo 4}

\section{TERMO DE CONSENTIMENTO LIVRE E ESCLARECIDO}

Atualmente, os agentes comunitários de saúde cuidam de 80 milhões de pessoas no país e diariamente presenciam situações estressantes no seu trabalho e na sua comunidade. Mesmo assim, existem poucas pesquisas que falem das condições de saúde do agente. Por isso, é importante estudar essas condições, para ter como sugerir mudanças e melhorar a qualidade de vida desse trabalhador.

A pesquisa tem como objetivos: estudar o desgaste profissional, identificar características das atividades dos agentes que podem estar relacionadas ao desgaste e estudar ansiedade e depressão nestes profissionais.

Para realizar a pesquisa, serão utilizadas três entrevistas: perguntas sobre o agente comunitário de saúde e características do trabalho, esgotamento profissional (maslach burnout inventory) e ansiedade e depressão (self reporting questionnaire), sendo assim, não se espera desconforto ou risco para o entrevistado.

As pessoas que participarem da pesquisa não terão benefícios diretos, mas os dados colhidos podem servir para abrir a conversa sobre esse tema e pensar estratégias que possam ajudar a diminuir o desgaste no dia-a-dia do agente.

O entrevistado pode ter acesso, a qualquer momento, às informações sobre a pesquisa (procedimentos, riscos e benefícios). Além disso, tem a liberdade de retirar seu consentimento e deixar de participar do estudo, sem que isto traga prejuízo.

Os pesquisadores garantem o sigilo e privacidade das informações fornecidas pelos entrevistados.

Caso o participante perceba a necessidade de acompanhamento por equipe de saúde mental deve solicitar ao entrevistador.

\section{CONSENTIMENTO PÓS-ESCLARECIDO}

Declaro que, após esclarecimento feito pelo pesquisador e ter entendido o que me foi explicado, consinto em participar desta Pesquisa.

São Paulo, de de 2006.

\section{PESQUISADOR}

ENTREVISTADO

Qualquer esclarecimento ou reclamação sobre os aspectos éticos da pesquisa, entrar em contato com: Comitê de Ética em Pesquisa da Secretaria Municipal de Saúde de São Paulo - R. General Jardim, 36, 2 andar t:: 32184043. smscep@prefeitura.sp.gov.br 